\title{
Design, synthesis, and biological evaluation of 1-ethyl-3- (thiazol-2-yl)urea derivatives as Escherichia coli DNA gyrase inhibitors
}

\author{
Tihomir Tomašič $^{1}$ (iD $\mid$ Michaela Barančoková $^{1}$ | Nace Zidar ${ }^{1}$ | Janez llaš ${ }^{1}$ | \\ Päivi Tammela ${ }^{2}$ | Danijel Kikelj ${ }^{1}$
}

${ }^{1}$ Faculty of Pharmacy, University of Ljubljana, Ljubljana, Slovenia

2 Division of Pharmaceutical Biosciences, Faculty of Pharmacy, University of Helsinki, Helsinki, Finland

\section{Correspondence}

Dr. Tihomir Tomašič, Faculty of Pharmacy, University of Ljubljana, Aškerčeva cesta 7 , Ljubljana 1000, Slovenia.

Email: tihomir.tomasic@ffa.uni-lj.si

\section{Funding information}

Slovenian Research Agency, Grant number: P1-0208; Marie Skłodowska-Curie ETN INTEGRATE, Grant number: 642620;

Academy of Finland, Grant numbers: 277001, 284477

\begin{abstract}
Discovery of novel DNA gyrase B inhibitors remains an attractive field in the search for new antibacterial drugs to overcome the known bacterial resistance mechanisms. In the present study, we designed and synthesized novel ethylurea derivatives of 4,5,6,7tetrahydrobenzo[1,2-d] thiazole-2,6-diamine, 2-(2-aminothiazol-4-yl)acetic acid, and benzo[1,2-d]thiazole-2,6-diamine and evaluated their Escherichia coli DNA gyrase inhibition. The most potent DNA gyrase inhibitors in the prepared library of compounds were benzo[1,2-d]thiazoles $32-34,36$, and 37 with $\mathrm{IC}_{50}$ values in the low micromolar range. The most promising inhibitors identified were evaluated against selected Gram-positive and Gram-negative bacterial strains. Compound $\mathbf{3} 3$ showed a MIC of $50 \mu \mathrm{M}$ against an E. coli efflux pump-defective strain, which suggests that efflux decreases the on-target concentrations of these compounds.
\end{abstract}

\section{KEYWORDS}

antibacterial, DNA gyrase, ethylurea, inhibitor, thiazole

\section{1 | INTRODUCTION}

Antibacterial drug resistance is a serious threat to human health, with bacteria such as Enterococcus faecium, Staphylococcus aureus, Klebsiella pneumoniae, Acinetobacter baumannii, and Enterobacter spp. (i.e., the "ESKAPE" bacteria) becoming multidrug resistant against the presently available antibiotics. ${ }^{[1]}$ To successfully fight infections with these "bad bugs" in the future, there is the continuous need for development of novel antibacterial agents that are not liable to the existing resistance mechanisms.

DNA gyrase and topoisomerase IV are type IIA bacterial topoisomerases that are involved in modulation of DNA topology

Abbreviations: EDC, 1-ethyl-3-(3-dimethylaminopropyl)carbodiimide; GyrA, DNA gyrase subunit A; GyrB, DNA gyrase subunit B; HOBt, 1-hydroxybenzotriazole; NMM, Nmethylmorpholine; ParC, topoisomerase IV subunit A; ParE, topoisomerase IV subunit B; RA, residual activity. during DNA replication, transcription, and recombination. As these enzymes are essential for cell viability and are conserved across all bacteria but are not found in human cells, this makes them attractive targets for antibacterial drug discovery. ${ }^{[2]}$

DNA gyrase and topoisomerase IV are heterotetrameric proteins, with DNA gyrase composed of two GyrA and two GyrB subunits $\left(A_{2} B_{2}\right)$, and topoisomerase IV of two ParC and ParE subunits $\left(C_{2} E_{2}\right)$. The GyrB and ParE subunits have the ATPase activities which are necessary for providing the energy for the supercoiling and decatenation reactions of the catalytic GyrA and ParC subunits. The aminocoumarin antibiotic novobiocin interacts with the ATP binding sites of GyrB and ParE, but it was withdrawn from the market because of its toxicity and lack of efficacy. ${ }^{[3]}$ In recent years, several structural classes of GyrB and ParE inhibitors have been discovered through high-throughput screening, virtual screening, and de-novo design, in both industry and academia. ${ }^{[3-5]}$ Structure-based optimization of hits has resulted in potent GyrB and/or 
ParE inhibitors that have antibacterial activities mainly against Grampositive bacteria, such as the cyclothialidine, ${ }^{[6]}$ ethylurea, ${ }^{[7-14]}$ pyrazolopyridone, ${ }^{[15,16]}$ and pyrrolamide ${ }^{[17-19]}$ classes (Figure 1). Rare examples of GyrB and ParE inhibitors with antibacterial activities against Gram-negative bacteria include pyrrolopyrimidines, ${ }^{[20]}$ pyrimidinoindoles, ${ }^{[21]}$ and some pyrrolamides ${ }^{[18]}$ (Figure 1). However, despite extensive efforts to develop new ATPase GyrB/ParE inhibitors, none has progressed beyond phase 1 clinical trials. ${ }^{[3]}$

We have recently designed and optimized several structural classes of pyrrolamide-based DNA gyrase and topoisomerase IV inhibitors, which were based on the 4,5,6,7-tetrahydrobenzo[1,2-d]thiazole-2,6-diamine, ${ }^{[22,23]}$ benzo[1,2- $d$ ]thiazole-2,6-diamine, ${ }^{[24]}$ 4aminopiperidine, ${ }^{[25]}$ and aniline ${ }^{[26,27]}$ scaffolds. In all of them, the 4,5-dibromopyrrolamide moiety was shown to be an important structural feature, as it is necessary to achieve potent Escherichia coli DNA gyrase inhibition. The 5,7-diarylbenzo[1,2-d]thiazole ethylureas (Figure 1) have already been reported to be potent DNA gyrase inhibitors and to have broad-spectrum Gram-positive antibacterial activities. ${ }^{[13,14]}$ We describe here the design and synthesis of novel thiazole-based ethylureas, and the evaluation of their E. coli DNA gyrase inhibition and antibacterial activities against selected Grampositive and Gram-negative bacteria.

\section{2 | RESULTS AND DISCUSSION}

\section{1 | Design}

The crystal structures of DNA gyrase in complexes with ethylureabased inhibitors ${ }^{[12]}$ show that their Asp73 (E. coli numbering) sidechain carboxylate forms two hydrogen bonds with the two $\mathrm{NH}$ groups of the ethylurea moiety, while the nitrogen atom of the central scaffold forms an additional hydrogen bond with a conserved water molecule (Figure 2). With this hydrogen bonding motif, ethylurea-based DNA gyrase inhibitors mimic the binding of the adenine ring of ATP, while additional interactions are formed with the amino acids of the lipophilic floor of the ATP binding site and with the Arg76 and Arg136 sidechains. ${ }^{[3,4]}$

Based on the described binding mode, we have designed novel DNA gyrase $B$ inhibitors bearing ethylurea moiety at position 2 of the thiazole moiety of the 4,5,6,7-tetrahydrobenzo[1,2-d]thiazole-2,6diamine (Figure 2, 5-15), 2-(2-aminothiazol-4-yl)acetic acid (Figure 2, 23-26), and benzo[1,2-d]thiazole-2,6-diamine (Figure 2, 30-38) central scaffolds. Additional substituents were introduced to interact with Arg76 and/or Arg136 side chains to improve binding affinity of the designed compounds. The design of all three of these series of compounds was supported by molecular docking to the E. coli DNA gyrase ATP binding site, which predicted the characteristic hydrogen bonding network that is shown in Figure 2.

\section{2 | Chemistry}

The synthesis of the 4,5,6,7-tetrahydrobenzo[1,2-d]thiazole-2,6diamine derivatives $\mathbf{5 - 1 5}$ is outlined in Scheme 1. The enantiomerically pure starting (S)-4,5,6,7-tetrahydrobenzo[1,2-d]thiazole-2,6-diamine (1) was synthesized according to the previously reported procedure. $^{[22,28]}$ In the first step, the 6-amino group was selectively protected as a tert-butylcarbamate using di-tert-butyl dicarbonate $\left(\mathrm{Boc}_{2} \mathrm{O}\right)$ in tetrahydrofuran, to obtain 2, and then the 2-amino group was reacted with ethyl isocyanate in chloroform to yield ethylurea 3. The Boc protecting group of $\mathbf{3}$ was removed by acidolysis with $\mathrm{HCl}$ gas generated in situ by the slow addition of acetyl chloride to methanol. The hydrochloride of 4 was obtained first, and was converted to its free<smiles>CCNC(=O)Nc1nc2cc(-c3cccnc3)cc(-c3ncccc3F)c2[nH]1</smiles>

benzimidazole ethylurea<smiles>CCNC(=O)Nc1nc2cc(-c3cnc(C(C)(C)O)nc3)cc(-c3ccccn3)c2s1</smiles>

benzothiazole ethylurea<smiles>CCCn1c(=O)ccc2c(-c3cnc(-c4cccnc4)s3)n[nH]c21</smiles>

pyrazolopyridone<smiles>CCc1[nH]c2nc(Sc3cnc4ccc[n+]([O-])c4c3)nc(N3C[C@H]4[C@@H](N)[C@H]4C3)c2c1Cl</smiles>

pyrrolopyrimidine<smiles>CNc1cc(F)cc2c1[nH]c1nc(Oc3cnc(C)nc3)nc(N3CC4[C@@H](N)C[C@]4(C)C3)c12</smiles>

pyrimidinoindole<smiles>COC[C@H](C)NC(=O)c1nc(N2CC[C@@H](NC(=O)c3[nH]c(C)c(Cl)c3Cl)[C@H](OC)C2)sc1C(=O)O</smiles>

pyrrolamide

FIGURE 1 Representative synthetic GyrB and/or ParE inhibitors 


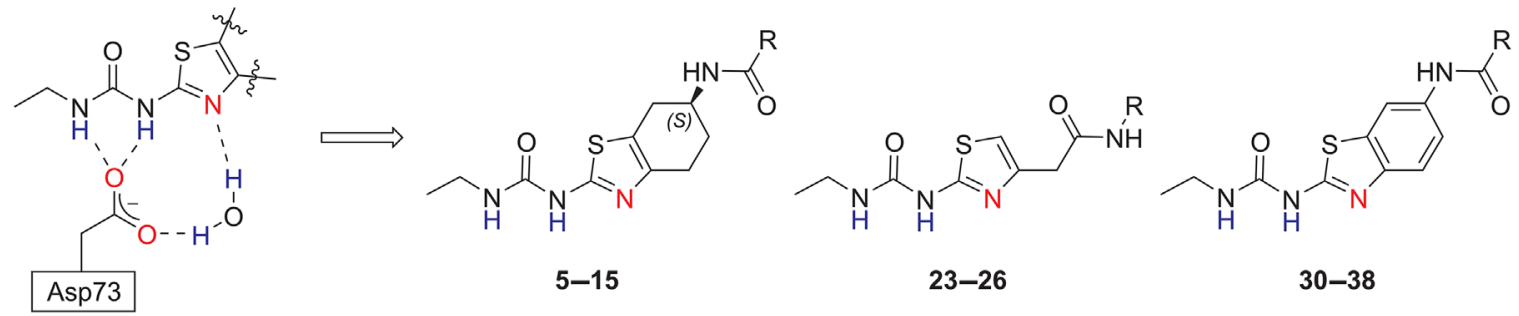

FIGURE 2 The hydrogen bonds of the thiazole-based ethylureas in the ATP binding site of DNA gyrase (E. coli numbering) and designed novel thiazole-based ethylurea DNA gyrase B inhibitors

base as this offered higher yields under weakly alkaline conditions of the following amide-bond formation step than seen for the reaction with the hydrochloride of 4 . Acylation of 4 with methyl malonyl chloride in 1,4-dioxane at room temperature yielded ester 5 , which was hydrolyzed to its acid derivative 6 under alkaline conditions, and converted to hydrazide 7 by ester hydrazinolysis. Amides 8 and 10-14 were prepared by coupling of amine 4 with the corresponding carboxylic acids, using EDC/HOBt coupling reagents. Benzoic acid derivative 9 was prepared by alkaline hydrolysis of ester 8 , while acidolysis of the tert-butylcarbamate 14 resulted in amine 15.

The designed 2-(2-aminothiazol-4-yl)acetic acid derivatives 23-26 were prepared according to the synthetic procedures presented in Scheme 2. Amine 16 was converted to tert-butylcarbamate 17 using $\mathrm{Boc}_{2} \mathrm{O}$, to acetamide 18 using acetyl chloride, and to ethylurea 19 using ethyl isocyanate. Compounds 17-19 were then hydrolyzed under alkaline conditions, to their carboxylic acid counterparts 20-22. Carboxylic acid 22 was coupled in the following step to methyl 3-aminobenzoate and methyl 4-aminobenzoate using EDC and HOBt, to obtain compounds 23 and 24. Their carboxylic acid derivatives $\mathbf{2 5}$ and $\mathbf{2 6}$ were prepared by alkaline hydrolysis.

Benzo[1,2-d]thiazoles $\mathbf{3 0 - 3 8}$ were synthesized as summarized in Scheme 3. In the first step, ethylurea $\mathbf{2 8}$ was prepared from amine 27 and ethyl isocyanate in toluene. Reduction of the nitro group of 28 by catalytic hydrogenation provided amine 29 , which was then used for the further synthesis. The 6-amino group of 29 was acylated with ethyl oxalyl chloride to provide ester 30 , which was hydrolyzed to acid 31 using $1 \mathrm{M} \mathrm{NaOH}$. The coupling of amine 29 with 2-(2aminothiazol-4-yl)acetic acids 20-22 (Scheme 2) yielded compounds 32-34. In addition, amine 35, which was obtained by Boc deprotection of 33 , was acylated with methyl malonyl chloride to<smiles>CCNC(=O)Nc1nc2c(s1)C[C@H](NC(=O)OC(C)(C)C)CC[C@@H]2NC(=O)OC(C)(C)C</smiles>

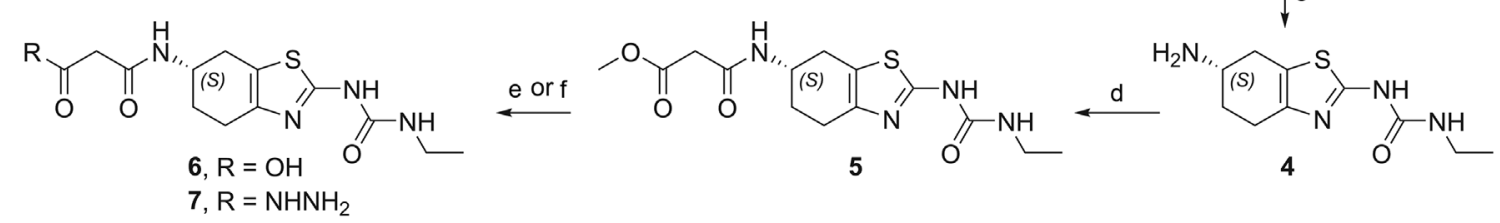<smiles>[R]OC(=O)c1cccc(C(=O)N[C@H]2CCc3nc(NC(=O)NCC)sc3C2)c1</smiles>

SCHEME 1 Synthesis of compounds 6-13. Reagents and conditions: a) $\mathrm{Boc}_{2} \mathrm{O}$, THF, r.t., 18 h. b) Ethyl isocyanate, $\mathrm{CHCl}_{3}$, r.t., $18 \mathrm{~h}$. c) Acetyl chloride, $\mathrm{MeOH}, 0^{\circ} \mathrm{C}, 1 \mathrm{~h}$, then r.t., 18 h. d) Methyl malonyl chloride, $\mathrm{Et}{ }_{3} \mathrm{~N}, 1,4$-dioxane, r.t., 18 h. e) 6: $1 \mathrm{M} \mathrm{NaOH}, \mathrm{MeOH} / \mathrm{H}_{2} \mathrm{O}$, r.t., 24 h. f) 7: Hydrazine hydrate, EtOH, $80^{\circ} \mathrm{C}, 18$ h. g) Carboxylic acid, EDC, HOBt, NMM, DMF, r.t., $24 \mathrm{~h}$ 


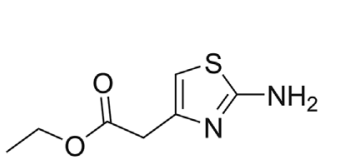

16<smiles>[R]C(=O)Nc1nc(CC(=O)OCC)cs1</smiles>

17, $\mathrm{R}=\mathrm{O} t \mathrm{Bu}$

18, $\mathrm{R}=\mathrm{Me}$

19, $\mathrm{R}=\mathrm{NHEt}$<smiles>[R]C(=O)Nc1nc(CC(=O)O)cs1</smiles>

20, $\mathrm{R}=\mathrm{OtBu}$

21, $\mathrm{R}=\mathrm{Me}$

22, $\mathrm{R}=\mathrm{NHEt}$<smiles>[R]c1cccc(NC(=O)Cc2csc(NC(=O)NCC)n2)c1</smiles>

22

SCHEME 2 Synthesis of compounds 17-26. Reagents and conditions: a) 17: $\mathrm{Boc}_{2} \mathrm{O}$, 4-dimethylaminopyridine, $\mathrm{CH}_{2} \mathrm{Cl}_{2}$, r.t., $18 \mathrm{~h}$. b) 18 : Acetyl chloride, $\mathrm{Et}_{3} \mathrm{~N}, \mathrm{CH}_{2} \mathrm{Cl}_{2}$, r.t., 4 h. c) 19: Ethyl isocyanate, $\mathrm{CHCl}_{3}, 50^{\circ} \mathrm{C}, 18$ h. d) $2 \mathrm{M} \mathrm{NaOH}, \mathrm{MeOH} / \mathrm{H}_{2} \mathrm{O}$, r.t., 18 h. e) Amine, EDC, $\mathrm{HOBt}$, NMM, DMF, r.t., $24 \mathrm{~h}$

give $\mathbf{3 6}$ and ethyl oxalyl chloride to give $\mathbf{3 7}$. Hydrolysis of $\mathbf{3 7}$ then gave carboxylic acid 38 .

\subsection{Biological evaluation}

Compounds 4-15, 23-26, and 30-38 were tested for E. coli DNA gyrase inhibition using an in vitro DNA gyrase supercoiling assay (Tables 1-3). These data are presented as residual activities of the $E$. coli DNA gyrase at 100 or $10 \mu \mathrm{M}$ of the tested compounds, or as $\mathrm{IC}_{50}$ values for the more active compounds, where the residual activities were $<50 \%$ at $100 \mu \mathrm{M}$ of the tested compounds. The selected final compounds were then screened for their antibacterial activities at
$50 \mu \mathrm{M}$ against two Gram-positive and two Gram-negative bacteria strains: S. aureus (ATCC 25923) and Enterococcus faecalis (ATCC 29212), and E. coli (ATCC 25922) and Pseudomonas aeruginosa (ATCC 27853), respectively. In addition, the compounds that showed $I C_{50}$ values less than $10 \mu \mathrm{M}$ against $E$. coli DNA gyrase were tested against two E. coli mutant strains: E. coli JD17464, an IpxC deletion mutant with a defective outer membrane due to impaired lipid A biosynthesis; and E. coli JW5503, which has a defective efflux pump due to deletion of a tolC gene. The data from these antibacterial activity evaluations are presented in Tables 1, 3, and 4.

The in vitro E. coli DNA gyrase inhibitory activities of the 4,5,6,7tetrahydrobenzo[1,2- $d$ ]thiazoles 4-15 and 2-(2-aminothiazol-4-yl)-<smiles>[R]Nc1nc2ccc([N+](=O)[O-])cc2s1</smiles><smiles>CCNC(=O)Nc1nc2ccc(N)cc2s1</smiles><smiles>[R]C(=O)C(=O)Nc1ccc2nc(NC(=O)NCC)sc2c1</smiles>

$\mathrm{d}$ 30, $\mathrm{R}=\mathrm{OEt}$ $31, \mathrm{R}=\mathrm{OH}$<smiles>[R]Nc1nc(CC(=O)Nc2ccc3nc(NC(=O)NCC)sc3c2)cs1</smiles>
32, $\mathrm{R}=\mathrm{CONHEt} \stackrel{\mathrm{f}}{\longrightarrow} \mathrm{35}, \mathrm{R}=\mathrm{H}$ 34, $\mathrm{R}=\mathrm{COMe}$<smiles>CCNC(=O)Nc1nc2ccc(NC(=O)Cc3csc(N)n3)cc2s1</smiles>
35

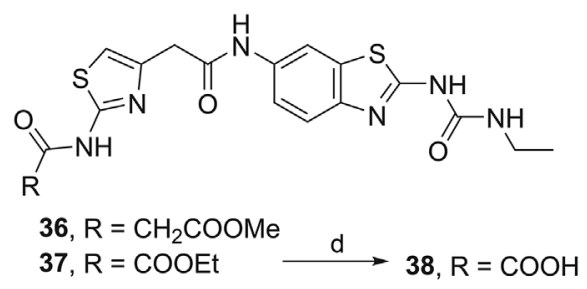

SCHEME 3 Synthesis of compounds 28-38. Reagents and conditions. a) Ethyl isocyanate, Et ${ }_{3} \mathrm{~N}$, toluene, reflux, 24h. b) $\mathrm{H}_{2}, \mathrm{Pd} / \mathrm{C}$, EtOH/ DMF, r.t., 48 h. c) Ethyl oxalyl chloride, Et $3 \mathrm{~N}, 1$,4-dioxane, r.t., 18 h. d) $1 \mathrm{M} \mathrm{NaOH}, \mathrm{MeOH} / \mathrm{H}_{2} \mathrm{O}$, r.t., 18 h. e) Carboxylic acid, EDC, $\mathrm{HOBt}$, $\mathrm{NMM}, \mathrm{DMF}$, r.t., $18 \mathrm{~h}$. f) Acetyl chloride, $\mathrm{MeOH}, 0^{\circ} \mathrm{C}, 1 \mathrm{~h}$, then r.t., $\left.18 \mathrm{~h} . \mathrm{g}\right)$ Methyl malonyl chloride, $\mathrm{Et}_{3} \mathrm{~N}, 1,4$-dioxane, r.t., $18 \mathrm{~h}$ 
TABLE 1 Inhibition of E. coli DNA gyrase and antibacterial activity of 4,5,6,7-tetrahydrobenzo[1,2-d]thiazoles 4-15

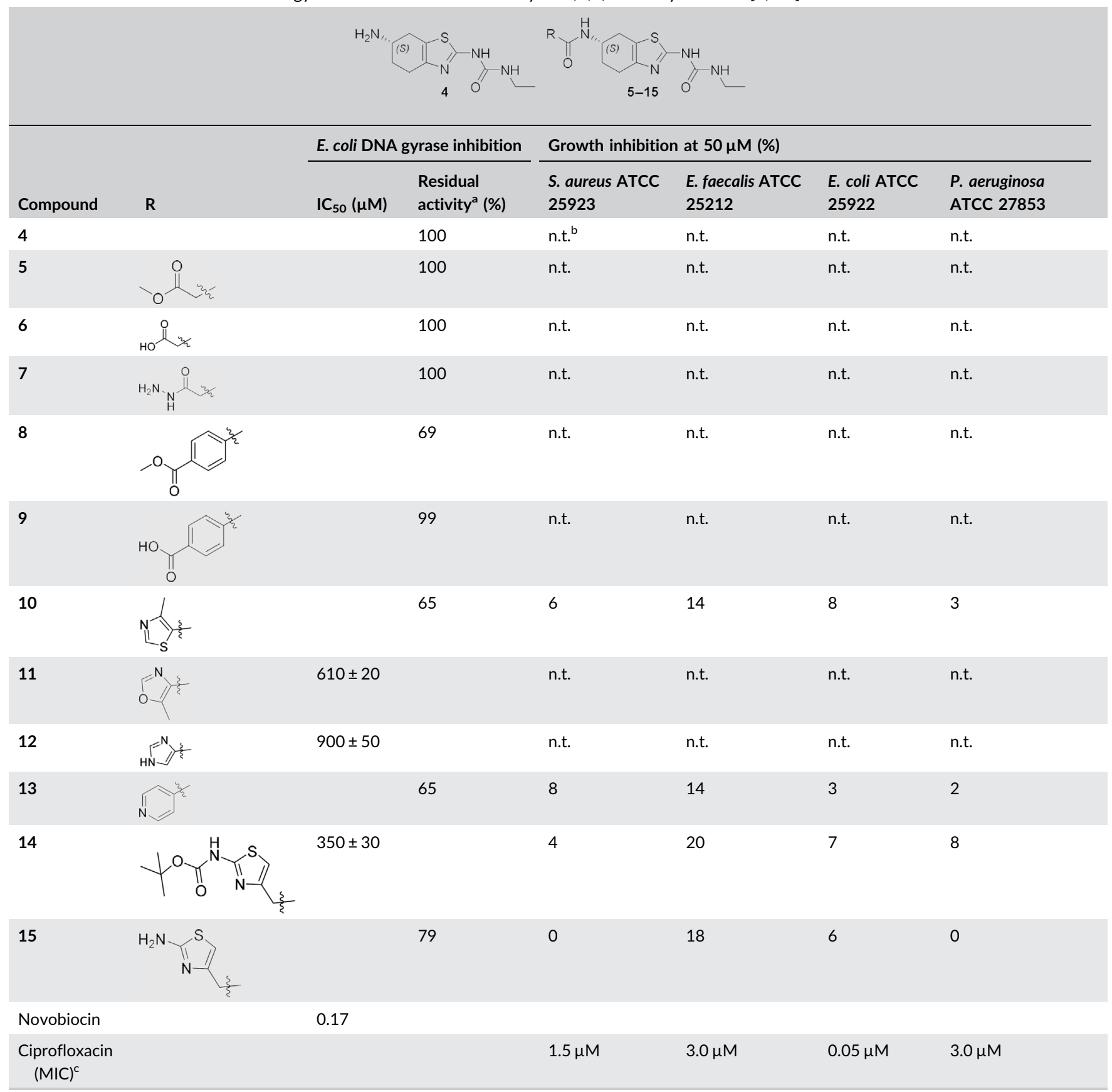

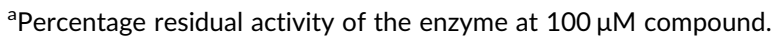

${ }^{b}$ n.t., not tested.

${ }^{\mathrm{c}}$ Data for ciprofloxacin bacterial growth inhibition given as MICs.

acetic acid derivatives 23-26 are presented in Tables 1 and 2. The results show that these compounds are poor $E$. coli DNA gyrase inhibitors, since only compounds 11,12 , and 14 inhibited the enzyme at high micromolar concentrations. In contrast, some of the benzo[1,2d] thiazoleureas 30-38 (Table 3) showed low micromolar E. coli DNA gyrase inhibition ( $\mathrm{IC}_{50}$ values between 3.9 and $8.3 \mu \mathrm{M}$ ). Comparison of the partially saturated 4,5,6,7-tetrahydrobenzo[1,2-d]thiazole 14 $\left(I C_{50}=350 \mu \mathrm{M}\right.$; Table 1$)$ and unsaturated benzo[1,2-d]thiazole 33
$\left(I C_{50}=3.9 \mu \mathrm{M}\right.$; Table 3$)$ suggests the importance of the cation- $\pi$ interactions between the Arg76 side-chain and the phenyl ring of these inhibitors (Figure 3). When the ethylurea moiety interacts with Asp73 in the DNA gyrase ATP binding site, the fused tetrahydrobenzene ring of compounds 5-15 is positioned under the Glu50-Arg76 salt bridge. Thus the cation- $\pi$ interactions between Arg76 and the inhibitors cannot be formed, which results in less potent inhibitory activities. A similar phenomenon was reported previously in a comparison of the 
TABLE 2 Inhibition of E. coli DNA gyrase by 2-(2-aminothiazol-4-yl)acetic acids 23-26

\begin{tabular}{lll} 
& \\
& & $\begin{array}{l}\text { E. coli DNA gyrase residual } \\
\text { activity }^{\mathrm{a}}(\%)\end{array}$ \\
\hline 23 & $3-\mathrm{COOMe}$ & 98 \\
24 & $4-\mathrm{COOMe}$ & 91 \\
25 & $3-\mathrm{COOH}$ & 74 \\
26 & $4-\mathrm{COOH}$ & 83 \\
\hline
\end{tabular}

These compounds were not tested for growth inhibition of S. aureus ATCC 25923, E. faecalis ATCC 25212, E. coli ATCC 25922, and P. aeruginosa ATCC 27853.

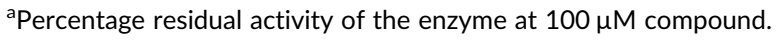

inhibitory activities of 4,5,6,7-tetrahydrobenzo[1,2- $d$ ] thiazoles ${ }^{[23]}$ and benzo[1,2- $d$ ] thiazoles ${ }^{[24]}$ with a pyrrolamide moiety at position 2 . The lack of this cation- $\pi$ interaction is probably also the reason for the inactivity of the 2-(2-aminothiazol-4-yl)acetic acid derivatives 23-26 (Table 2).

All of the tested compounds were only weakly active or were inactive at $50 \mu \mathrm{M}$ against Gram-negative $E$. coli and P. aeruginosa and Gram-positive S. aureus and E. faecalis (Tables 1 and 3). One of the possible reasons for these weak antibacterial activities against these bacteria might be their low micromolar DNA gyrase inhibition. Some previously reported ethylurea-based compounds were shown to have nanomolar DNA gyrase inhibition and antibacterial activity against Gram-positive bacteria. ${ }^{[7-14]}$ However, these compounds usually lack activity against Gram-negative bacteria, which is often a consequence of the efflux of these inhibitors. Similarly, in the present study, the improved MIC values against the $E$. coli mutant strain JW5503 for inhibitor $33(\mathrm{MIC}=50 \mu \mathrm{M})$ (Table 4) suggests that these compounds are efflux pump substrates. Furthermore, as no improvements in the MICs against E. coli JD17464 were seen (Table 4), the efflux of these compounds and not their insufficient penetration through the cell wall appears to be the major reason for the absence of their antibacterial activity.

\section{3 | CONCLUSIONS}

A focused library of novel 4,5,6,7-tetrahydrobenzo[1,2-d]thiazole-, 2-(2aminothiazol-4-yl)acetic acid-, and benzo[1,2- $d$ ] thiazole-based ethylurea derivatives was designed and prepared as potential DNA gyrase B inhibitors. The molecular docking studies showed hydrogen bond network formed with Asp73, structural water molecule and Arg136 in the ATPbinding site of E. coli DNA gyrase. The results of the in vitro E. coli DNA gyrase supercoiling assay showed that the most potent of these compounds were benzo[1,2-d]thiazoles 32-34, 36, and 37 with $\mathrm{IC}_{50}$ values in the low micromolar range, while 4,5,6,7-tetrahydrobenzo[1,2-d]- thiazole and 2-(2-aminothiazol-4-yl)acetic acid derivatives were only weakly active or inactive. Evaluation of the antibacterial activities showed weak inhibition of bacterial growth at $50 \mu \mathrm{M}$ against S. aureus, E. faecalis, $E$. coli, and $P$. aeruginosa. In both Gram-positive and Gram-negative bacteria this could be the result of only micromolar enzyme inhibition and/or poor penetration through the bacterial cell wall. In addition, the in vitro assays on the E. coli efflux-pump-deficient strain (JW5503) indicated that these compounds are efflux pump substrates in $E$. coli, which will result in reduced cytoplasmic concentrations and hence poor antibacterial activity against Gram-negative strains. Nevertheless, these structure-activity relationships provide a basis for further optimization of this structural class of DNA gyrase inhibitors.

\section{4 | EXPERIMENTAL}

\section{1 | Chemistry}

\subsection{1 | General procedures}

Chemicals were obtained from Acros Organics (Geel, Belgium), SigmaAldrich (St. Louis, MO, USA), and TCl Europe N.V. (Zwijndrecht, Belgium) and used without further purification. Analytical TLC was performed on silica gel Merck $60 \mathrm{~F}_{254}$ plates $(0.25 \mathrm{~mm})$, using visualization with UV light and spray reagents. Column chromatography was carried out on silica gel 60 (particle size 240-400 mesh). HPLC analyses were performed on Agilent Technologies 1100 instrument with G1365B UV-VIS detector, G1316A thermostat and G1313A autosampler using Agilent Eclipse Plus C18 column $(5 \mu \mathrm{m}$, $4.6 \times 150 \mathrm{~mm}$ ) using Method A: mobile phase: $0.1 \%$ trifluoroacetic acid in water (A) and acetonitrile (B); gradient: 2 min 95\% A, 90\% A to $10 \% \mathrm{~A}$ in $12 \mathrm{~min}, 10 \% \mathrm{~A}$ to $5 \% \mathrm{~A}$ in $1 \mathrm{~min}$, then $5 \mathrm{~min} 5 \% \mathrm{~A}$; flow rate $1.0 \mathrm{~mL} / \mathrm{min}$; injection volume: $10 \mu \mathrm{L}$. All tested compounds were $\geq 95 \%$ pure by HPLC. Melting points were determined on a Reichert hot stage microscope and are uncorrected. ${ }^{1} \mathrm{H}$ and ${ }^{13} \mathrm{C}$ NMR spectra were recorded at 400 and $100 \mathrm{MHz}$, respectively, on a Bruker AVANCE III 400 spectrometer (Bruker Corporation, Billerica, MA, USA) in DMSO- $d_{6}$ or $\mathrm{CDCl}_{3}$ solutions, with TMS as the internal standard. Mass spectra were obtained using a VG Analytical Autospec Q mass spectrometer (Fisons, VG Analytical, Manchester, UK). Optical rotations were measured on a PerkinElmer $241 \mathrm{MC}$ polarimeter. The reported values for specific rotation are average values of five successive measurements using an integration time of $5 \mathrm{~s}$.

The InChl codes of the investigated compounds together with some biological activity data are provided as Supporting Information.

\subsection{2 | Synthetic procedures}

tert-Butyl (S)-(2-amino-4,5,6,7-tetrahydrobenzo[1,2-d]thiazol-6yl)carbamate (2)

A solution of (S)-4,5,6,7-tetrahydrobenzo[1,2-d]thiazole-2,6-diamine (1) (3.002 g, $17.8 \mathrm{mmol})$ in tetrahydrofuran (THF) (100 mL) was cooled to $0^{\circ} \mathrm{C}$ on an ice bath. Then a solution of di-tert-butyl dicarbonate 
TABLE 3 Inhibition of E. coli DNA gyrase and antibacterial activity of benzo[1,2-d]thiazoles 30-38

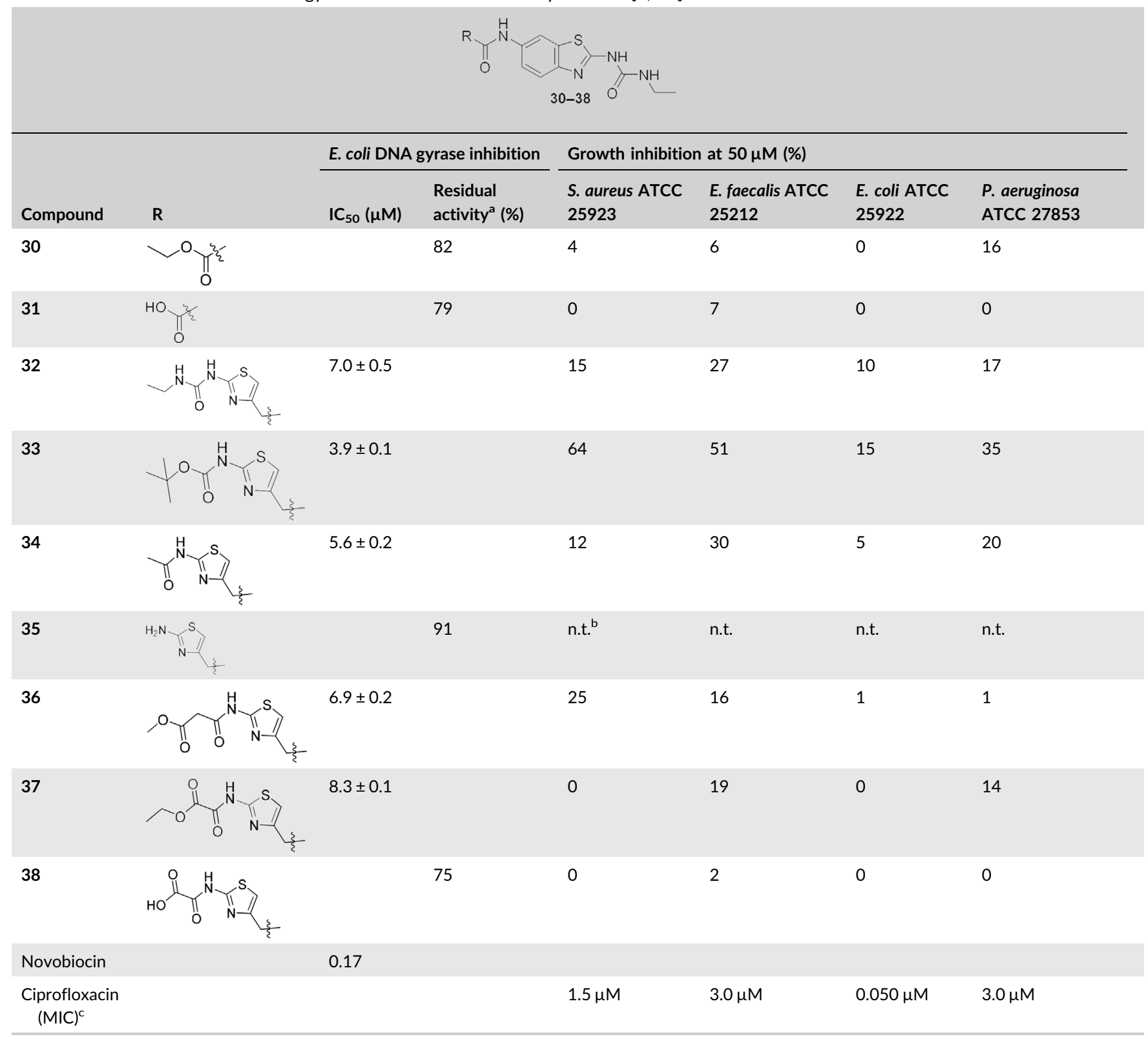

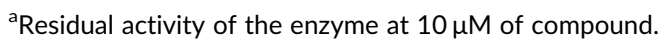

${ }^{b}$ n.t., not tested.

${ }^{\mathrm{C}}$ Data for ciprofloxacin bacterial growth inhibition given as MICs.

$\left(\mathrm{Boc}_{2} \mathrm{O}\right)(4.068 \mathrm{~g}, 18.7 \mathrm{mmol})$ in THF $(30 \mathrm{~mL})$ was added dropwise over $20 \mathrm{~min}$. The reaction mixture was stirred at room temperature overnight. The solvent was removed under reduced pressure and the crude product dissolved in ethyl acetate $(100 \mathrm{~mL})$. Organic phase was successively washed with saturated aqueous $\mathrm{NaHCO}_{3}$ solution $(100 \mathrm{~mL})$ and brine $(100 \mathrm{~mL})$, dried over $\mathrm{Na}_{2} \mathrm{SO}_{4}$, filtered and the solvent removed under reduced pressure. Product was used without further purification. Yield: $4.79 \mathrm{~g}(100 \%) ;$ white solid; $\mathrm{mp} 140-$ $142^{\circ} \mathrm{C} ;[a]_{\mathrm{D}}-40.3$ (c 0.26, MeOH); ${ }^{1} \mathrm{H}$ NMR (400 MHz, DMSO- $\left.d_{6}\right): \delta$ $1.38\left(\mathrm{~s}, 9 \mathrm{H}, \mathrm{C}\left(\mathrm{CH}_{3}\right)_{3}\right), 1.54-1.65\left(\mathrm{~m}, 1 \mathrm{H}, \mathrm{H}_{\mathrm{A}}-7\right), 1.80-1.86(\mathrm{~m}, 1 \mathrm{H}$, $\left.\mathrm{H}_{\mathrm{B}}-7\right), \quad 2.31-2.47\left(\mathrm{~m}, 3 \mathrm{H}, \mathrm{H}_{\mathrm{A}}-4, \mathrm{H}-5\right), 2.68$ (dd, $1 \mathrm{H}$, $J_{1}=14.8 \mathrm{~Hz}, J_{2}=5.5 \mathrm{~Hz}, \mathrm{H}_{\mathrm{B}}-4$ ), 3.57-3.69 (m, 1H, CㅡN $\left.2 \mathrm{H}, \mathrm{NH}_{2}\right), 6.94(\mathrm{~d}, 1 \mathrm{H}, J=7.9 \mathrm{~Hz}, \mathrm{NH}) \mathrm{ppm} ;{ }^{13} \mathrm{C} \mathrm{NMR}(100 \mathrm{MHz}$, DMSO- $\left.d_{6}\right): \delta 24.9,28.2(3 \mathrm{C}), 28.87,28.94,46.8,77.6,112.4,144.1$, 154.9, $166.1 \mathrm{ppm}$.

tert-Butyl (S)-(2-(3-ethylureido)-4,5,6,7-tetrahydrobenzo[1,2-d]thiazol-6-yl)carbamate (3)

A solution of 2 ( $4.460 \mathrm{~g}, 16.6 \mathrm{mmol})$ in chloroform ( $100 \mathrm{~mL}$ ) was cooled to $0^{\circ} \mathrm{C}$ on an ice bath under an argon atmosphere. Then ethyl isocyanate ( $1.44 \mathrm{~mL}, 18.2 \mathrm{mmol}$ ) was added dropwise over $20 \mathrm{~min}$. The reaction mixture was stirred at room temperature overnight. Reaction mixture was transferred to the separating funnel and successively washed with saturated aqueous $\mathrm{NaHCO}_{3}$ solution $(2 \times 25 \mathrm{~mL})$ and 
TABLE 4 Inhibition of E. coli DNA gyrase and antibacterial activities of compounds 32-34, 36, and 37 against wild-type E. coli and two mutant $E$. coli strains

\begin{tabular}{|c|c|c|c|c|c|}
\hline \multirow[b]{2}{*}{ Compound } & \multirow[b]{2}{*}{ E. coli DNA gyrase $\mathrm{IC}_{50}(\mu \mathrm{M})$} & \multicolumn{4}{|l|}{ Growth inhibition } \\
\hline & & $\begin{array}{l}\text { E. coli ATCC } 25922 \\
(\%)^{\mathrm{a}}\end{array}$ & MIC $(\mu \mathrm{M})$ & $(\%)^{a}$ & $\frac{\text { E. coli JD17464 }}{(\%)^{\mathrm{a}}}$ \\
\hline 32 & $7.0 \pm 0.5$ & 10 & & 0 & 2 \\
\hline 33 & $3.9 \pm 0.1$ & 15 & 50 & & 37 \\
\hline 34 & $5.6 \pm 0.2$ & 5 & & 4 & 15 \\
\hline 37 & $8.3 \pm 0.1$ & 0 & & 0 & 6 \\
\hline Ciprofloxacin (MIC) & & $0.050 \mu \mathrm{M}$ & $0.015 \mu \mathrm{M}$ & & $0.12 \mu \mathrm{M}$ \\
\hline
\end{tabular}

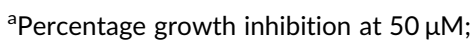

${ }^{b}$ Data for ciprofloxacin bacterial growth inhibition given as MICs.

brine (100 mL), dried over $\mathrm{Na}_{2} \mathrm{SO}_{4}$, filtered and the solvent removed under reduced pressure. Crude product was purified by column chromatography using dichloromethane/methanol (30:1) as eluent. Yield: $2.29 \mathrm{~g}(40.7 \%)$; white solid; $\mathrm{mp} 183-185^{\circ} \mathrm{C}$; [a $]_{\mathrm{D}}-15.6$ (c 0.22 , $\mathrm{MeOH}) ;{ }^{1} \mathrm{H}$ NMR $\left(400 \mathrm{MHz}, \mathrm{DMSO}-d_{6}\right): \delta 1.05(\mathrm{t}, 3 \mathrm{H}, J=7.2 \mathrm{~Hz}$, $\left.\mathrm{CH}_{2} \mathrm{CH}_{3}\right), 1.40\left(\mathrm{~s}, 9 \mathrm{H}, 3 \times \mathrm{CH}_{3}\right), 1.61-1.71\left(\mathrm{~m}, 1 \mathrm{H}, \mathrm{H}_{\mathrm{A}}-7\right), 1.86-1.94(\mathrm{~m}$, $\left.1 \mathrm{H}, \mathrm{H}_{\mathrm{B}}-7\right), 2.38-2.47\left(\mathrm{~m}, 1 \mathrm{H}, \mathrm{H}_{\mathrm{A}}-5\right), 2.55-2.71\left(\mathrm{~m}, 2 \mathrm{H}, \mathrm{H}_{\mathrm{B}}-5, \mathrm{H}_{\mathrm{A}}-4\right)$, $2.81\left(\mathrm{dd}, 1 \mathrm{H}, J_{1}=15.7 \mathrm{~Hz}, J_{2}=5.0 \mathrm{~Hz}, \mathrm{H}_{\mathrm{B}}-4\right), 3.09-3.16(\mathrm{~m}, 2 \mathrm{H}$, $\left.\mathrm{CH}_{2} \mathrm{CH}_{3}\right), 3.58-3.76(\mathrm{~m}, 1 \mathrm{H}, \mathrm{CHNH}), 6.50(\mathrm{t}, 1 \mathrm{H}, J=5.0 \mathrm{~Hz}$, $\mathrm{NHCH}_{2} \mathrm{CH}_{3}$ ), 6.99 (d, $1 \mathrm{H}, J=7.9 \mathrm{~Hz}, \mathrm{~N} \underline{\mathrm{HCH}}$ ), 10.11 (s, $\left.1 \mathrm{H}, \mathrm{N} \underline{\mathrm{HCO}}\right)$ ppm; ${ }^{13} \mathrm{C}$ NMR (100 MHz, DMSO- $\left.d_{6}\right): \delta 15.2,24.8,28.2$ (3C), 28.5, 28.9, 34.1, 46.4, 77.6, 117.4, 144.8, 153.6, 155.0, 157.6 ppm; HRMS $\left(E S I^{+}\right) \mathrm{m} / \mathrm{z}$ for $\mathrm{C}_{15} \mathrm{H}_{24} \mathrm{~N}_{4} \mathrm{O}_{3} \mathrm{~S}\left([\mathrm{M}+\mathrm{H}]^{+}\right)$: calcd. 341.1647, found 341.1652 .

(S)-1-(6-Amino-4,5,6,7-tetrahydrobenzo[1,2-d]thiazol-2-yl)-3ethylurea (4)

Methanol $(30 \mathrm{~mL})$ was cooled on an ice bath and then acetyl chloride $(4.80 \mathrm{~mL}, 67.4 \mathrm{mmol})$ was added dropwise. The mixture was stirred at

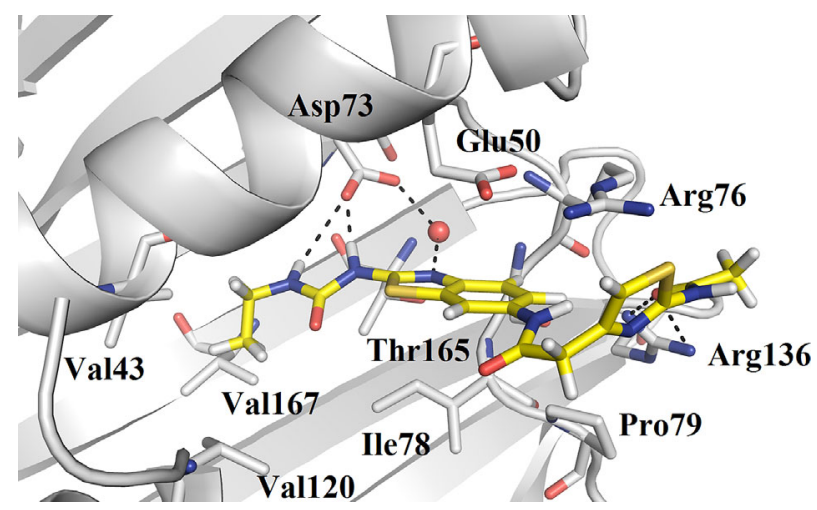

FIGURE 3 The docking binding mode of inhibitor 34 (in yellow) in the ATP binding site of E. coli DNA gyrase B (in gray, PDB code: $4 \mathrm{DUH}^{[29]}$ ). The ligand and the neighboring protein side-chains are shown as stick models, colored according to the chemical atom type (blue, N; red, O; orange, S; green, $\mathrm{Cl}$ ). Water molecule is presented as a red sphere. Hydrogen bonds are indicated by black dotted lines $0^{\circ} \mathrm{C}$ for $30 \mathrm{~min}$ and then solution of $3(2.292 \mathrm{~g}, 6.74 \mathrm{mmol})$ in methanol $(20 \mathrm{~mL})$ was added. Reaction mixture was stirred at $0^{\circ} \mathrm{C}$ for $1 \mathrm{~h}$ and then at room temperature overnight. The solvent was evaporated under reduced pressure, crude product dissolved in a small volume of water and then $1 \mathrm{M} \mathrm{NaOH}$ was added to reach $\mathrm{pH} \sim 12$. Off-white precipitate $(1.615 \mathrm{~g}, 99.8 \%)$ was filtered off and dried. $\mathrm{mp} 121-123^{\circ} \mathrm{C}$; $[a]_{\mathrm{D}}-34.5$ (c 0.24, MeOH); ${ }^{1} \mathrm{H}$ NMR (400 MHz, DMSO- $\left.d_{6}\right): \delta 1.05(\mathrm{t}$, $\left.3 \mathrm{H}, J=7.2 \mathrm{~Hz}, \mathrm{CH}_{2} \mathrm{CH}_{3}\right), 1.48-1.59\left(\mathrm{~m}, 1 \mathrm{H}, \mathrm{H}_{\mathrm{A}}-7\right), 1.82-1.89(\mathrm{~m}, 1 \mathrm{H}$, $\mathrm{H}_{\mathrm{B}}-7$ ), 2.25-2.32 (m, $1 \mathrm{H}, \mathrm{H}_{\mathrm{A}}-5$ ), 2.44-2.60 (m, 2H, $\mathrm{H}_{\mathrm{A}}-4, \mathrm{H}_{\mathrm{B}}-5$, signal partially overlapped with DMSO- $\left.d_{5}\right), 2.77\left(\mathrm{dd}, 1 \mathrm{H}, J_{1}=15.6 \mathrm{~Hz}\right.$, $\left.J_{2}=4.8 \mathrm{~Hz}, \mathrm{H}_{\mathrm{B}}-4\right), 3.01-3.07(\mathrm{~m}, 1 \mathrm{H}, \mathrm{C} \underline{\mathrm{HNH}}), 3.10-3.16(\mathrm{~m}, 2 \mathrm{H}$, $\left.\mathrm{CH}_{2} \mathrm{CH}_{3}\right), 6.58$ (s, $1 \mathrm{H}, \mathrm{NHCH}_{2} \mathrm{CH}_{3}$ ) ppm; signals for $\mathrm{NH}_{2}$ and $\mathrm{NHCO}$ are not seen in the spectrum; ${ }^{13} \mathrm{C}$ NMR $\left(100 \mathrm{MHz}\right.$, DMSO- $\left.d_{6}\right): \delta 15.7$, 25.1, 32.2, 32.5, 34.5, 47.9, 118.3, 143.3, 154.3, 158.0 ppm; HRMS $\left(\mathrm{ESI}^{+}\right) \mathrm{m} / \mathrm{z}$ for $\mathrm{C}_{10} \mathrm{H}_{16} \mathrm{~N}_{4} \mathrm{OS}\left([\mathrm{M}+\mathrm{H}]^{+}\right)$: calcd. 241.1123, found 241.1117 .

Methyl (S)-3-((2-(3-ethylureido)-4,5,6,7-tetrahydrobenzo[1,2-d]thiazol-6-yl)amino)-3-oxopropanoate (5)

To a solution of $4(0.159 \mathrm{~g}, 0.66 \mathrm{mmol})$ and $\mathrm{Et}_{3} \mathrm{~N}(0.138 \mathrm{~mL}, 0.99 \mathrm{mmol})$ in 1,4-dioxane $(30 \mathrm{~mL})$, methyl 3-chloro-3-oxopropanoate $(0.092 \mathrm{~mL}$, $0.86 \mathrm{mmol}$ ) was added dropwise under an argon atmosphere. Reaction mixture was stirred at room temperature for $18 \mathrm{~h}$. Solvent was removed under reduced pressure and to the crude product ethyl acetate $(20 \mathrm{~mL})$ was added. The precipitate was filtered off, washed with ethyl acetate $(5 \mathrm{~mL})$, dried and then purified by flash column chromatography using dichloromethane/methanol (40:1) as eluent. Yield: 0.130 g (57.7\%); off-white solid; $\mathrm{mp} 198-200^{\circ} \mathrm{C}$; $[\mathrm{a}]_{\mathrm{D}}-10.1$ (c $0.21, \mathrm{MeOH}) ;{ }^{1} \mathrm{H}$ NMR (400 MHz, DMSO- $\left.d_{6}\right): \delta 1.05(\mathrm{t}, 3 \mathrm{H}, J=7.2 \mathrm{~Hz}$, $\mathrm{CH}_{2} \mathrm{CH}_{3}$ ), 1.71-1.80 (m, 1H, $\mathrm{H}_{\mathrm{A}}-7$ ), 1.84-1.92 (m, $\left.1 \mathrm{H}, \mathrm{H}_{\mathrm{B}}-7\right), 2.42-$ $2.46\left(\mathrm{~m}, 1 \mathrm{H}, \mathrm{H}_{\mathrm{A}}-4\right), 2.56-2.63\left(\mathrm{~m}, 2 \mathrm{H}, \mathrm{H}_{\mathrm{A}}-5, \mathrm{H}_{\mathrm{B}}-4\right), 2.87(\mathrm{dd}, 1 \mathrm{H}$, $\left.J_{1}=16.0 \mathrm{~Hz}, J_{2}=5.5 \mathrm{~Hz}, \mathrm{H}_{\mathrm{B}}-5\right), 3.09-3.16\left(\mathrm{~m}, 2 \mathrm{H}, \mathrm{CH}_{2} \mathrm{CH}_{3}\right), 3.25$ (s, $2 \mathrm{H}, \mathrm{COCH}_{2} \mathrm{CO}$ ), 3.62 (s, 3H, $\mathrm{COOCH}_{3}$ ), 3.99-4.06 (m, $1 \mathrm{H}, \mathrm{CHNH}$ ), 6.76 (br s, $1 \mathrm{H}, \mathrm{NH}^{\mathrm{H}} \mathrm{H}_{2} \mathrm{CH}_{3}$ ), 8.18 (d, $1 \mathrm{H}, J=7.6 \mathrm{~Hz}, \mathrm{CON} \underline{\mathrm{H}} \mathrm{CH}$ ), 10.14 (brs, $1 \mathrm{H}, \mathrm{NHCO}$ ) ppm; HRMS (ESI') $\mathrm{m} / \mathrm{z}$ for $\mathrm{C}_{14} \mathrm{H}_{19} \mathrm{~N}_{4} \mathrm{O}_{4} \mathrm{~S}\left([\mathrm{M}-\mathrm{H}]^{-}\right)$: calcd. 339.1127, found 339.1121; HPLC: method A, $t_{r} 9.07 \mathrm{~min}(100 \%$ at $254 \mathrm{~nm})$. 
(S)-3-((2-(3-Ethylureido)-4,5,6,7-tetrahydrobenzo[1,2-d]thiazol6-yl)amino)-3-oxopropanoic acid (6)

To a solution of $5(0.037 \mathrm{~g}, 0.11 \mathrm{mmol})$ in methanol $(10 \mathrm{~mL}), 1 \mathrm{M}$ $\mathrm{NaOH}(0.44 \mathrm{~mL}, 0.44 \mathrm{mmol})$ was added and the reaction mixture stirred at room temperature for $3 \mathrm{~h}$. Methanol was evaporated under reduced pressure and reaction mixture extracted with ethyl acetate $(10 \mathrm{~mL})$. Water phase was acidified with $1 \mathrm{M} \mathrm{HCl}$ to $\mathrm{pH} \sim 2$, precipitate was filtered off and purified by flash column chromatography using dichloromethane/methanol/acetic acid (5:1:0.1) as eluent. Yield: $0.021 \mathrm{~g}(59.2 \%)$; off-white solid; $\mathrm{mp} 130-132^{\circ} \mathrm{C} ;[\mathrm{a}]_{\mathrm{D}}$ -12.6 (c 0.23, MeOH); ${ }^{1} \mathrm{H}$ NMR (400 MHz, DMSO- $\left.d_{6}\right): \delta 1.05$ (t, $3 \mathrm{H}$, $\left.J=7.2 \mathrm{~Hz}, \mathrm{CH}_{2} \mathrm{CH}_{3}\right), 1.70-1.80\left(\mathrm{~m}, 1 \mathrm{H}, \mathrm{H}_{\mathrm{A}}-7\right), 1.84-1.90(\mathrm{~m}, 1 \mathrm{H}$, $\left.\mathrm{H}_{\mathrm{B}}-7\right), 2.41-2.45\left(\mathrm{~m}, 1 \mathrm{H}, \mathrm{H}_{\mathrm{A}}-4\right), 2.56-2.68\left(\mathrm{~m}, 2 \mathrm{H}, \mathrm{H}_{\mathrm{A}}-5, \mathrm{H}_{\mathrm{B}}-4\right)$, $2.87\left(\mathrm{dd}, 1 \mathrm{H}, J_{1}=15.9 \mathrm{~Hz}, J_{2}=4.9 \mathrm{~Hz}, \mathrm{H}_{\mathrm{B}}-5\right), 3.09-3.16(\mathrm{~m}, 2 \mathrm{H}$, $\mathrm{CH}_{2} \mathrm{CH}_{3}$ ), 3.22 (s, 2H, COCH${ }_{2} \mathrm{CO}$ ), 3.99-4.12 (m, 1H, $\underline{\mathrm{H}} \underline{\mathrm{HNH}}$ ), 6.54 (t, $\left.1 \mathrm{H}, J=5.4 \mathrm{~Hz}, \mathrm{NHCH}_{2} \mathrm{CH}_{3}\right), 8.20$ (d, $1 \mathrm{H}, J=7.5 \mathrm{~Hz}, \mathrm{CON} \underline{\mathrm{H} C H}$ ), 10.17 (br s, $1 \mathrm{H}, \mathrm{NHCO}$ ) ppm; signal for $\mathrm{COOH}$ not seen in the spectrum; HRMS $\left(E S I^{-}\right) \mathrm{m} / z$ for $\mathrm{C}_{13} \mathrm{H}_{17} \mathrm{~N}_{4} \mathrm{O}_{4} \mathrm{~S}\left([\mathrm{M}-\mathrm{H}]^{-}\right)$: calcd. 325.0971, found 325.0977; HPLC: method A, $t_{r} 8.59 \min (95.1 \%$ at $254 \mathrm{~nm})$.

(S)-N-(2-(3-Ethylureido)-4,5,6,7-tetrahydrobenzo[1,2-d]thiazol6-yl)-3-hydrazinyl-3-oxopropanamide (7)

To a solution of $5(0.080 \mathrm{~g}, 0.24 \mathrm{mmol})$ in ethanol $(4 \mathrm{~mL})$, hydrazine monohydrate $(0.143 \mathrm{~mL}, 2.40 \mathrm{mmol})$ was added and the reaction mixture stirred at $80^{\circ} \mathrm{C}$ overnight. Ethanol was evaporated under reduced pressure and the residue purified by flash column chromatography using dichloromethane/methanol $(9: 1)$ as eluent. Yield: $0.075 \mathrm{~g}$ (93.8\%); gray solid; $\mathrm{mp} 241-243^{\circ} \mathrm{C}$; $[a]_{D}-16.3$ (c 0.20 , $\mathrm{MeOH}) ;{ }^{1} \mathrm{H}$ NMR $\left(400 \mathrm{MHz}, \mathrm{DMSO}-d_{6}\right): \delta 1.05(\mathrm{t}, 3 \mathrm{H}, J=7.1 \mathrm{~Hz}$, $\mathrm{CH}_{2} \mathrm{CH}_{3}$ ), 1.70-1.80 (m, 1H, $\left.\mathrm{H}_{\mathrm{A}}-7\right), 1.83-1.90$ (m, 1H, $\left.\mathrm{H}_{\mathrm{B}}-7\right), 2.40-$ $2.45\left(\mathrm{~m}, 1 \mathrm{H}, \mathrm{H}_{\mathrm{A}}-4\right), 2.58-2.63\left(\mathrm{~m}, 2 \mathrm{H}, \mathrm{H}_{\mathrm{A}}-5, \mathrm{H}_{\mathrm{B}}-4\right), 2.87$ (dd, $1 \mathrm{H}$, $\left.J_{1}=15.4 \mathrm{~Hz}, J_{2}=4.5 \mathrm{~Hz}, \mathrm{H}_{\mathrm{B}}-5\right), 2.98\left(\mathrm{~s}, 2 \mathrm{H}, \mathrm{COCH}_{2} \mathrm{CO}\right), 3.09-3.16(\mathrm{~m}$, $2 \mathrm{H}, \mathrm{CH}_{2} \mathrm{CH}_{3}$ ), 3.97-4.06 (m, 1H, CN $\mathrm{HH}$ ), 4.24 (br s, 2H, $\mathrm{NHNH}_{2}$ ), 6.52 $\left(\mathrm{t}, 1 \mathrm{H}, J=4.7 \mathrm{~Hz}, \mathrm{NHCH}_{2} \mathrm{CH}_{3}\right), 8.12(\mathrm{~d}, 1 \mathrm{H}, J=7.6 \mathrm{~Hz}, \mathrm{CONHCH}), 9.08$ (s, $1 \mathrm{H}, \mathrm{NHNH}_{2}$ ), 10.17 (br s, $1 \mathrm{H}, \mathrm{NHCO}$ ) ppm; HRMS (ESI ${ }^{-}$) $\mathrm{m} / \mathrm{z}$ for $\mathrm{C}_{13} \mathrm{H}_{19} \mathrm{~N}_{6} \mathrm{O}_{3} \mathrm{~S}\left([\mathrm{M}-\mathrm{H}]^{-}\right)$: calcd. 339.1239, found 339.1234; HPLC: method $A, t_{r} 7.99 \min (100 \%$ at $254 \mathrm{~nm})$.

\subsection{3 | General procedure A}

A solution of carboxylic acid $(1 \mathrm{mmol})$ in $\mathrm{N}, \mathrm{N}$-dimethylformamide $(10 \mathrm{~mL})$ was cooled to $0^{\circ} \mathrm{C}$ and then EDC $(1.2 \mathrm{mmol})$ and $\mathrm{HOBt}$ $(1.3 \mathrm{mmol})$ were added. $\mathrm{pH}$ was adjusted to 8 with $\mathrm{N}$-methylmorpholine and the reaction mixture stirred for $20 \mathrm{~min}$ at $0^{\circ} \mathrm{C}$. Then amine ( $1 \mathrm{mmol}$ ) was added and reaction mixture stirred overnight at room temperature. The solvent was evaporated in vacuo and the oily residue dissolved in ethyl acetate $(30 \mathrm{~mL})$ and washed successively with $10 \%$ citric acid $(2 \times 30 \mathrm{~mL})$, saturated aqueous $\mathrm{NaHCO}_{3}$ solution $(2 \times 30 \mathrm{~mL})$, and brine $(30 \mathrm{~mL})$. The organic phase was dried over $\mathrm{Na}_{2} \mathrm{SO}_{4}$, filtered and the solvent evaporated under reduced pressure.
Methyl (S)-3-((2-(3-ethylureido)-4,5,6,7-tetrahydrobenzo[1,2-d]thiazol-6-yl)carbamoyl)benzoate (8)

Compound was prepared from $4(0.195 \mathrm{~g}, 0.81 \mathrm{mmol})$ and $3-$ (methoxycarbonyl)benzoic acid $(0.146 \mathrm{~g}, 0.81 \mathrm{mmol})$ according to the general procedure $A$. Crude product was purified by column chromatography using dichloromethane/methanol (20:1) as eluent. Yield: $0.138 \mathrm{~g}$ (42.2\%); yellowish solid; $\mathrm{mp} 174-176^{\circ} \mathrm{C}$; $[a]_{D}-12.6$ (c 0.30, DMF); ${ }^{1} \mathrm{H}$ NMR (400 MHz, DMSO-d $)_{6}$ : $\delta 1.06(\mathrm{t}, 3 \mathrm{H}, J=7.1 \mathrm{~Hz}$, $\mathrm{CH}_{2} \mathrm{CH}_{3}$ ), 1.86-1.91 (m, 1H, $\left.\mathrm{H}_{\mathrm{A}}-7\right), 2.00-2.03\left(\mathrm{~m}, 1 \mathrm{H}, \mathrm{H}_{\mathrm{B}}-7\right), 2.63-$ $2.70\left(\mathrm{~m}, 3 \mathrm{H}, \mathrm{H}_{\mathrm{A}}-5, \mathrm{H}-4\right), 2.95\left(\mathrm{dd}, 1 \mathrm{H}, J_{1}=15.3 \mathrm{~Hz}, J_{2}=5.2 \mathrm{~Hz}, \mathrm{H}_{\mathrm{B}}-5\right)$, 3.12-3.18 (m, $\left.2 \mathrm{H}, \mathrm{CH}_{2} \mathrm{CH}_{3}\right), 3.90\left(\mathrm{~s}, 3 \mathrm{H}, \mathrm{COOCH}_{3}\right), 4.20-4.29(\mathrm{~m}, 1 \mathrm{H}$, CㅂNH), $6.52\left(\mathrm{t}, 1 \mathrm{H}, J=5.6 \mathrm{~Hz}, \mathrm{NHCH}_{2} \mathrm{CH}_{3}\right), 7.64(\mathrm{t}, 1 \mathrm{H}, J=7.8 \mathrm{~Hz}, \mathrm{Ar}-$ $\mathrm{H}-5), 8.10-8.15$ (m, 2H, Ar-H-4, Ar-H-6), 8.46 (t, 1H, J = 1.6 Hz, Ar-H2), $8.73(\mathrm{~d}, 1 \mathrm{H}, J=7.7 \mathrm{~Hz}, \mathrm{CON} \underline{\mathrm{HCH}}$ ), 10.14 (s, 1H, NHCO) ppm; ${ }^{13} \mathrm{C}$ NMR (100 MHz, DMSO- $\left.d_{6}\right): \delta 15.2,24.9,28.2,28.6,34.1,46.2$, 52.3, 117.4, 128.0, 128.9, 129.7, 131.6, 132.1, 135.1, 142.9, 153.7, 157.5, 164.9, 165.8 ppm; HRMS $\left(\mathrm{ESI}^{-}\right) \mathrm{m} / \mathrm{z}$ for $\mathrm{C}_{19} \mathrm{H}_{21} \mathrm{~N}_{4} \mathrm{O}_{4} \mathrm{~S}\left([\mathrm{M}-\mathrm{H}]^{-}\right)$: calcd. 401.1284, found 401.1286; HPLC: method A, $t_{r} 10.89 \mathrm{~min}$ (98.7\% at $254 \mathrm{~nm})$.

(S)-3-((2-(3-Ethylureido)-4,5,6,7-tetrahydrobenzo[1,2-d]thiazol6-yl)carbamoyl)benzoic acid (9)

To a solution of $8(0.138 \mathrm{~g}, 0.34 \mathrm{mmol})$ in methanol $(5 \mathrm{~mL}), 1 \mathrm{M} \mathrm{NaOH}$ $(1.02 \mathrm{~mL}, 1.02 \mathrm{mmol})$ was added and the reaction mixture stirred at room temperature overnight. Methanol was evaporated under reduced pressure and reaction mixture extracted with ethyl acetate $(10 \mathrm{~mL})$. Water phase was acidified with $1 \mathrm{M} \mathrm{HCl}$ to $\mathrm{pH} \sim 2$. Precipitate was filtered off and dried. Water phase was extracted with ethyl acetate $(3 \times 20 \mathrm{~mL})$, combined organic phases were washed with brine, dried over $\mathrm{Na}_{2} \mathrm{SO}_{4}$, filtered and the solvent evaporated under reduced pressure. Yield: $0.132 \mathrm{~g}$ (99.1\%); pink solid; $\mathrm{mp} 220-222^{\circ} \mathrm{C}$; $[a]_{D}-16.3$ (c $0.29, \mathrm{MeOH}) ;{ }^{1} \mathrm{H}$ NMR $\left(400 \mathrm{MHz}, \mathrm{DMSO}-d_{6}\right): \delta 1.07$ (t, $3 \mathrm{H}$, $\left.J=7.2 \mathrm{~Hz}, \mathrm{CH}_{2} \mathrm{CH}_{3}\right), 1.85-1.93\left(\mathrm{~m}, 1 \mathrm{H}, \mathrm{H}_{\mathrm{A}}-7\right), 1.99-2.05\left(\mathrm{~m}, 1 \mathrm{H}, \mathrm{H}_{\mathrm{B}^{-}}\right.$ 7), 2.61-2.73 (m, 3H, H $\left.\mathrm{A}_{\mathrm{A}}-5, \mathrm{H}-4\right), 2.97$ (dd, $1 \mathrm{H}, J_{1}=15.5 \mathrm{~Hz}, J_{2}=4.9 \mathrm{~Hz}$, $\left.\mathrm{H}_{\mathrm{B}}-5\right), 3.14-3.18\left(\mathrm{~m}, 2 \mathrm{H}, \mathrm{CH}_{2} \mathrm{CH}_{3}\right), 4.22-4.30$ (m, 1H, $\left.\mathrm{C} \underline{H N H}\right), 7.14$ (br $\left.\mathrm{s}, 1 \mathrm{H}, \mathrm{NHCH}_{2} \mathrm{CH}_{3}\right), 7.61(\mathrm{t}, 1 \mathrm{H}, J=7.7 \mathrm{~Hz}, \mathrm{Ar}-\mathrm{H}-5), 8.08-8.12(\mathrm{~m}, 2 \mathrm{H}$, $\mathrm{Ar}-\mathrm{H}-4, \operatorname{Ar}-\mathrm{H}-6), 8.44$ (s, $1 \mathrm{H}, \operatorname{Ar}-\mathrm{H}-2), 8.74(\mathrm{~d}, 1 \mathrm{H}, J=7.5 \mathrm{~Hz}$, $\mathrm{CON} \underline{\mathrm{HCH}}$ ), 10.99 (br s, $1 \mathrm{H}, \mathrm{NHCO}$ ) ppm; signal for $\mathrm{COOH}$ not seen in the spectrum; ${ }^{13} \mathrm{C}$ NMR $\left(100 \mathrm{MHz}\right.$, DMSO- $\left.d_{6}\right): \delta 14.9,22.7,27.5$, 27.9, 34.3, 45.4, 118.3, 128.1, 128.7, 130.8, 131.7, 131.8, 134.8, 137.0, 152.7, 159.9, 165.2, $166.9 \mathrm{ppm}$; HRMS $\left(\mathrm{ESI}^{-}\right) \mathrm{m} / \mathrm{z}$ for $\mathrm{C}_{18} \mathrm{H}_{19} \mathrm{~N}_{4} \mathrm{O}_{4} \mathrm{~S}\left([\mathrm{M}-\mathrm{H}]^{-}\right)$: calcd. 387.1127, found 387.1118; HPLC: method $A, t_{r} 9.95 \mathrm{~min}(98.4 \%$ at $254 \mathrm{~nm})$.

(S)-N-(2-(3-Ethylureido)-4,5,6,7-tetrahydrobenzo[1,2-d] thiazol6-yl)-4-methylthiazole-5-carboxamide (10)

Compound was prepared from $4(0.084 \mathrm{~g}, 0.35 \mathrm{mmol})$ and $4-$ methylthiazole-5-carboxylic acid $(0.050 \mathrm{~g}, 0.35 \mathrm{mmol})$ according to the general procedure $A$. Crude product was purified by column chromatography using dichloromethane/methanol (20:1) as eluent. Yield: $0.092 \mathrm{~g}(72.0 \%)$; yellow solid; $\mathrm{mp} 198-200^{\circ} \mathrm{C}$; $[a]_{D}-8.0$ (c 0.26 , $\mathrm{MeOH}$ ); ${ }^{1} \mathrm{H}$ NMR (400 MHz, DMSO-d $)_{6}: \delta 1.05(\mathrm{t}, 3 \mathrm{H}, J=7.1 \mathrm{~Hz}$, $\mathrm{CH}_{2} \mathrm{CH}_{3}$ ), 1.80-1.90 (m, 1H, $\left.\mathrm{H}_{\mathrm{A}}-7\right), 1.96-2.03\left(\mathrm{~m}, 1 \mathrm{H}, \mathrm{H}_{\mathrm{B}}-7\right), 2.56$ (s, 
$\left.3 \mathrm{H}, \mathrm{CH}_{3}\right), 2.58-2.69\left(\mathrm{~m}, 3 \mathrm{H}, \mathrm{H}_{\mathrm{A}}-5, \mathrm{H}-4\right), 2.92$ (dd, $1 \mathrm{H}, J_{1}=15.3 \mathrm{~Hz}$, $\left.J_{2}=4.5 \mathrm{~Hz}, \mathrm{H}_{\mathrm{B}}-5\right), 3.09-3.16\left(\mathrm{~m}, 2 \mathrm{H}, \mathrm{CH}_{2} \mathrm{CH}_{3}\right), 4.11-4.21(\mathrm{~m}, 1 \mathrm{H}$, CㅡNH), 6.73 (s, $1 \mathrm{H}, \mathrm{NHCH}_{2} \mathrm{CH}_{3}$ ), 8.37 (d, $1 \mathrm{H}, J=7.7 \mathrm{~Hz}, \mathrm{CON} \underline{\mathrm{HCH}}$ ), 9.05 (s, 1H, Ar-H), 10.25 (s, 1H, NHCO) ppm; ${ }^{13} \mathrm{C} \mathrm{NMR} \mathrm{(100} \mathrm{MHz,}$ DMSO- $\left.d_{6}\right): \delta 15.2,16.7,24.8,28.0,28.4,34.0,46.2,117.1,126.3$, 142.8, 153.4, 153.9, 154.2, 157.5, 160.9 ppm; HRMS (ESI $\left.{ }^{+}\right) \mathrm{m} / \mathrm{z}$ for $\mathrm{C}_{15} \mathrm{H}_{19} \mathrm{~N}_{5} \mathrm{O}_{2} \mathrm{~S}_{2}\left([\mathrm{M}+\mathrm{H}]^{+}\right)$: calcd. 366.1058, found 366.1058; HPLC: method $A, t_{r} 9.56 \min (100 \%$ at $254 \mathrm{~nm})$.

(S)-N-(2-(3-Ethylureido)-4,5,6,7-tetrahydrobenzo[1,2-d]thiazol6-yl)-5-methylisoxazole-4-carboxamide (11)

Compound was prepared from $4(0.082 \mathrm{~g}, 0.34 \mathrm{mmol})$ and $4-$ methylisoxazole-4-carboxylic acid $(0.050 \mathrm{~g}, 0.34 \mathrm{mmol})$ according to the general procedure $\mathbf{A}$. Crude product was purified by column chromatography using dichloromethane/methanol (40:1) as eluent. Yield: $0.030 \mathrm{~g}(21.8 \%)$; yellow solid; $\mathrm{mp} 160-162^{\circ} \mathrm{C}$; $[\mathrm{a}]_{\mathrm{D}}-10.0$ (c 0.19 , DMF); ${ }^{1} \mathrm{H}$ NMR (400 MHz, DMSO- $\left.d_{6}\right): \delta 1.05(\mathrm{t}, 3 \mathrm{H}, J=7.2 \mathrm{~Hz}$, $\mathrm{CH}_{2} \mathrm{C}_{3}$ ), 1.65-1.72 (m, 1H, $\mathrm{H}_{\mathrm{A}}-7$ ), 1.76-1.93 (m, 1H, $\mathrm{H}_{\mathrm{B}}-7$ ), 1.99 (s, $3 \mathrm{H}, \mathrm{CH}_{3}$ ), 2.54-2.64 (m, 3H, $\left.\mathrm{H}_{\mathrm{A}}-5, \mathrm{H}-4\right), 2.92$ (dd, $1 \mathrm{H}, J_{1}=16.1 \mathrm{~Hz}$, $\left.J_{2}=4.8 \mathrm{~Hz}, \mathrm{H}_{\mathrm{B}}-5\right), 3.09-3.16\left(\mathrm{~m}, 2 \mathrm{H}, \mathrm{CH}_{2} \mathrm{CH}_{3}\right), 3.52-3.61(\mathrm{~m}, 1 \mathrm{H}$, CㅂNH), 6.77 (s, $1 \mathrm{H}, \mathrm{NH}^{\mathrm{H}} \mathrm{H}_{2} \mathrm{CH}_{3}$ ), 6.98 (d, $1 \mathrm{H}, J=6.0 \mathrm{~Hz}, \mathrm{CON} \underline{\mathrm{H}} \mathrm{CH}$ ), 8.41 (s, 1H, Ar-H), 10.27 (s, 1H, NHCO) ppm; HRMS (ESI ${ }^{+}$) m/z for $\mathrm{C}_{15} \mathrm{H}_{19} \mathrm{~N}_{5} \mathrm{O}_{3} \mathrm{~S}\left([\mathrm{M}+\mathrm{H}]^{+}\right)$: calcd. 350.1287, found 350.1286; HPLC: method $\mathrm{A}, t_{\mathrm{r}} 11.09 \mathrm{~min}(95.0 \%$ at $254 \mathrm{~nm})$.

(S)-N-(2-(3-Ethylureido)-4,5,6,7-tetrahydrobenzo[1,2-d]thiazol6-yl)-1H-imidazole-4-carboxamide (12)

Compound was prepared from $4(0.108 \mathrm{~g}, 0.45 \mathrm{mmol})$ and $1 \mathrm{H}$ imidazole-4-carboxylic acid $(0.050 \mathrm{~g}, 0.45 \mathrm{mmol})$ according to the general procedure A. Crude product was purified by column chromatography using dichloromethane/methanol (9:1) as eluent. Yield: $0.005 \mathrm{~g}(3.4 \%)$; yellow solid; $\mathrm{mp} 180-182^{\circ} \mathrm{C}$; $[\alpha]_{\mathrm{D}}-18.3$ (c 0.20 , $\mathrm{MeOH}$ ); ${ }^{1} \mathrm{H}$ NMR (400 MHz, MeOD- $d_{4}$ ): $\delta 1.19$ (t, $3 \mathrm{H}, J=7.2 \mathrm{~Hz}$, $\mathrm{CH}_{2} \mathrm{CH}_{3}$ ), 1.97-2.04 (m, 1H, $\mathrm{H}_{\mathrm{A}}-7$ ), 2.12-2.19 (m, $1 \mathrm{H}, \mathrm{H}_{\mathrm{B}}-7$ ), 2.68$2.82\left(\mathrm{~m}, 3 \mathrm{H}, \mathrm{H}_{\mathrm{A}}-5, \mathrm{H}-4\right), 3.08$ (dd, $\left.1 \mathrm{H}, J_{1}=15.5 \mathrm{~Hz}, J_{2}=5.6 \mathrm{~Hz}, \mathrm{H}_{\mathrm{B}}-5\right)$, 3.23-3.31 (m, 2H, $\left.\mathrm{CH}_{2} \mathrm{CH}_{3}\right), 4.37-4.43(\mathrm{~m}, 1 \mathrm{H}, \mathrm{C} \underline{\mathrm{HNH}}), 7.70(\mathrm{~d}, 1 \mathrm{H}$, $J=1.0 \mathrm{~Hz}, \mathrm{Ar}-\mathrm{H}), 7.74(\mathrm{~d}, 1 \mathrm{H}, J=1.0 \mathrm{~Hz}, \mathrm{Ar}-\mathrm{H}) \mathrm{ppm}$; signals for $\mathrm{NH}$ groups are not seen in the spectrum; HRMS $\left(\mathrm{ESI}^{+}\right) \mathrm{m} / \mathrm{z}$ for $\mathrm{C}_{14} \mathrm{H}_{18} \mathrm{~N}_{6} \mathrm{O}_{2} \mathrm{~S}\left([\mathrm{M}+\mathrm{H}]^{+}\right)$: calcd. 335.1290, found 335.1297; HPLC: method $\mathrm{A}, \mathrm{t}_{\mathrm{r}} 8.48 \mathrm{~min}(100 \%$ at $254 \mathrm{~nm})$.

(S)-N-(2-(3-Ethylureido)-4,5,6,7-tetrahydrobenzo[1,2-d]thiazol6-yl)isonicotinamide (13)

Compound was prepared from $4(0.82 \mathrm{~g}, 0.34 \mathrm{mmol})$ and pyridine-4carboxylic acid $(0.042 \mathrm{~g}, 0.34 \mathrm{mmol})$ according to the general procedure $\mathrm{A}$. Crude product was purified by column chromatography using dichloromethane/methanol $(20: 1)$ as eluent. Yield: $0.013 \mathrm{~g}$ (11.0\%); white solid; mp $125-127^{\circ} \mathrm{C}$; $[a]_{D}-6.3$ (c 0.18 , DMF); ${ }^{1} \mathrm{H}$ NMR (400 MHz, DMSO- $\left.d_{6}\right): \delta 1.06\left(\mathrm{t}, 3 \mathrm{H}, J=7.2 \mathrm{~Hz}, \mathrm{CH}_{2} \mathrm{CH}_{3}\right)$, 1.82-1.92 (m, $\left.1 \mathrm{H}, \mathrm{H}_{\mathrm{A}}-7\right)$, 1.98-2.05 (m, $\left.1 \mathrm{H}, \mathrm{H}_{\mathrm{B}}-7\right), 2.61-2.69(\mathrm{~m}, 3 \mathrm{H}$, $\left.\mathrm{H}_{\mathrm{A}}-5, \mathrm{H}-4\right), 2.95$ (dd, $\left.1 \mathrm{H}, J_{1}=15.3 \mathrm{~Hz}, J_{2}=4.8 \mathrm{~Hz}, \mathrm{H}_{\mathrm{B}}-5\right), 3.10-3.17(\mathrm{~m}$, $\left.2 \mathrm{H}, \mathrm{CH}_{2} \mathrm{CH}_{3}\right), 4.17-4.27(\mathrm{~m}, 1 \mathrm{H}, \mathrm{C} \underline{\mathrm{HNH}}), 6.51(\mathrm{t}, 1 \mathrm{H}, J=5.5 \mathrm{~Hz}$, $\mathrm{NHCH}_{2} \mathrm{CH}_{3}$ ), 7.77 (dd, $\left.2 \mathrm{H}, J_{1}=4.4 \mathrm{~Hz}, J_{2}=1.7 \mathrm{~Hz}, \mathrm{Ar}-\mathrm{H}\right), 8.73$ (dd, $2 \mathrm{H}$,
$J_{1}=4.4 \mathrm{~Hz}, J_{2}=1.7 \mathrm{~Hz}, \mathrm{Ar}-\mathrm{H}$ ), 8.77 (d, 1H, J = 7.7 Hz, CHNH), 10.14 (s, $1 \mathrm{H}, \mathrm{NHCO}) \mathrm{ppm} ;{ }^{13} \mathrm{C}$ NMR (100 MHz, DMSO- $\left.d_{6}\right): \delta 15.2,24.5,28.1$, 28.5, 34.1, 46.2, 117.2, 121.4 (2C), 141.5, 150.1 (2C), 153.7, 157.7, 157.9, $164.4 \mathrm{ppm}$; HRMS $\left(\mathrm{ESI}^{+}\right) \mathrm{m} / \mathrm{z}$ for $\mathrm{C}_{16} \mathrm{H}_{19} \mathrm{~N}_{5} \mathrm{O}_{2} \mathrm{~S}\left([\mathrm{M}+\mathrm{H}]^{+}\right)$: calcd. 346.1338, found 346.1330; HPLC: method $A, t_{r} 8.65$ min $(95.1 \%$ at $254 \mathrm{~nm})$.

tert-Butyl (S)-(4-(2-((2-(3-ethylureido)-4,5,6,7-tetrahydrobenzo [1,2-d]thiazol-6-yl)amino)-2-oxoethyl)thiazol-2-yl)carbamate

Compound was prepared from $4(0.067 \mathrm{~g}, 0.28 \mathrm{mmol})$ and 2 - $(2$-( (tertbutoxycarbonyl)amino)thiazol-4-yl)acetic acid $(0.071 \mathrm{~g}, 0.28 \mathrm{mmol})$ according to the general procedure A. Yield: $0.098 \mathrm{~g}$ (74.2\%); yellow solid; mp $140-142^{\circ} \mathrm{C} ;[a]_{D}-6.0$ (c $\left.0.27, \mathrm{MeOH}\right) ;{ }^{1} \mathrm{H} \mathrm{NMR}(400 \mathrm{MHz}$, DMSO-d $\left.d_{6}\right): \delta 1.05$ (t, $\left.3 \mathrm{H}, J=7.2 \mathrm{~Hz}, \mathrm{CH}_{2} \mathrm{CH}_{3}\right), 1.48\left(\mathrm{~s}, 9 \mathrm{H}, \mathrm{C}\left(\mathrm{CH}_{3}\right)_{3}\right)$, 1.68-1.79 (m, $\left.1 \mathrm{H}, \mathrm{H}_{\mathrm{A}}-7\right), 1.84-1.94\left(\mathrm{~m}, 1 \mathrm{H}, \mathrm{H}_{\mathrm{B}}-7\right), 2.39-2.47(\mathrm{~m}, 1 \mathrm{H}$, $\left.\mathrm{H}_{\mathrm{A}}-4\right), 2.54-2.70\left(\mathrm{~m}, 2 \mathrm{H}, \mathrm{H}_{\mathrm{B}}-4, \mathrm{H}_{\mathrm{A}}-5\right), 2.86\left(\mathrm{dd}, 1 \mathrm{H}, J_{1}=16.1 \mathrm{~Hz}\right.$, $\left.J_{2}=5.5 \mathrm{~Hz}, \mathrm{H}_{\mathrm{B}}-5\right), 3.08-3.17\left(\mathrm{~m}, 2 \mathrm{H}, \mathrm{CH}_{2} \mathrm{CH}_{3}\right), 3.42$ (s, $2 \mathrm{H}, \mathrm{Ar}-\mathrm{CH}_{2}$ ), 3.95-4.02 (m, 1H, CㅌNH), 6.51 (t, $\left.1 \mathrm{H}, J=5.6 \mathrm{~Hz}, \mathrm{NHCH}_{2} \mathrm{CH}_{3}\right), 6.81$ (s, $1 \mathrm{H}, \mathrm{Ar}-\mathrm{H}$ ), 8.11 (d, $1 \mathrm{H}, J=7.5 \mathrm{~Hz}, \mathrm{CHNH}$ ), 10.12 (s, 1H, NHCO), 11.39 (s, $1 \mathrm{H}, \mathrm{NHCO}) \mathrm{ppm} ;{ }^{13} \mathrm{C} \mathrm{NMR}\left(100 \mathrm{MHz}, \mathrm{CDCl}_{3}\right): \delta 15.3,28.2$ (3C), 29.0, 35.0, 39.1, 44.8, 55.4, 66.9, 77.2, 109.8, 115.6, 116.1, 117.5, 143.2, 152.4, 154.6, 159.8, $161.2 \mathrm{ppm}$; HRMS $\left(\mathrm{ESI}^{+}\right) \mathrm{m} / \mathrm{z}$ for $\mathrm{C}_{20} \mathrm{H}_{28} \mathrm{~N}_{6} \mathrm{O}_{4} \mathrm{~S}_{2}\left([\mathrm{M}+\mathrm{H}]^{+}\right)$: calcd. 481.1692, found 481.1685; HPLC: method $\mathrm{A}, t_{\mathrm{r}} 11.28 \mathrm{~min}(100 \%$ at $254 \mathrm{~nm})$.

(S)-2-(2-Aminothiazol-4-yl)-N-(2-(3-ethylureido)-4,5,6,7tetrahydrobenzo[1,2-d] thiazol-6-yl)acetamide (15)

Methanol $(5 \mathrm{~mL})$ was cooled on an ice bath and then acetyl chloride $(0.108 \mathrm{~mL}, 1.52 \mathrm{mmol})$ was added dropwise. The mixture was stirred at $0^{\circ} \mathrm{C}$ for $30 \mathrm{~min}$ and then solution of $14(0.073 \mathrm{~g}, 0.15 \mathrm{mmol})$ in methanol $(5 \mathrm{~mL})$ was added. Reaction mixture was stirred at $0^{\circ} \mathrm{C}$ for $1 \mathrm{~h}$ and then at room temperature overnight. Then solvent was evaporated under reduced pressure and crude product purified by column chromatography using dichloromethane/methanol (9:1) as eluent. Yield: $0.032 \mathrm{~g}(55.2 \%) ;$ yellow solid; $\mathrm{mp} 120-122^{\circ} \mathrm{C}$; $[\mathrm{a}]_{\mathrm{D}}-5.7$ (c 0.22 , $\mathrm{MeOH}$ ); ${ }^{1} \mathrm{H}$ NMR (400 MHz, DMSO- $\left.d_{6}\right): \delta 1.03(\mathrm{t}, 3 \mathrm{H}, J=7.2 \mathrm{~Hz}$, $\mathrm{CH}_{2} \mathrm{CH}_{3}$ ), 1.67-1.78 (m, 1H, $\left.\mathrm{H}_{\mathrm{A}}-7\right)$, 1.84-1.93 (m, 1H, $\left.\mathrm{H}_{\mathrm{B}}-7\right), 2.53-$ $2.60\left(\mathrm{~m}, 3 \mathrm{H}, \mathrm{H}-4, \mathrm{H}_{\mathrm{A}}-5\right), 2.84\left(\mathrm{dd}, 1 \mathrm{H}, J_{1}=15.2 \mathrm{~Hz}, J_{2}=5.3 \mathrm{~Hz}, \mathrm{H}_{\mathrm{B}}-5\right)$, 3.06-3.12 (m, $2 \mathrm{H}, \mathrm{CH}_{2} \mathrm{CH}_{3}$ ), $3.26\left(\mathrm{~s}, 2 \mathrm{H}, \mathrm{Ar}-\mathrm{CH}_{2}\right), 3.92-4.00(\mathrm{~m}, 1 \mathrm{H}$,

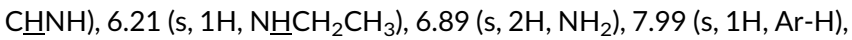
8.14 (d, $1 \mathrm{H}, J=7.7 \mathrm{~Hz}, \mathrm{CHN} \underline{\mathrm{H}}$ ), 11.08 (br s, 1H, NHCO) ppm; HRMS $\left(E S I^{+}\right) \mathrm{m} / \mathrm{z}$ for $\mathrm{C}_{15} \mathrm{H}_{20} \mathrm{~N}_{6} \mathrm{O}_{2} \mathrm{~S}_{2}\left([\mathrm{M}+\mathrm{H}]^{+}\right)$: calcd. 381.1167, found 381.1162; HPLC: method $A, t_{r} 8.60 \mathrm{~min}$ ( $96.5 \%$ at $254 \mathrm{~nm}$ ).

Ethyl 2-(2-((tert-butoxycarbonyl)amino)thiazol-4-yl)acetate (17) To a solution of $16(1.077 \mathrm{~g}, 5.78 \mathrm{mmol})$ and catalytic amount of 4dimethylaminopyridine in dichloromethane $(50 \mathrm{~mL})$ a solution of ditert-butyl dicarbonate $\left(\mathrm{Boc}_{2} \mathrm{O}\right)(1.640 \mathrm{~g}, 7.52 \mathrm{mmol})$ in dichloromethane $(20 \mathrm{~mL})$ was added dropwise over $20 \mathrm{~min}$. The reaction mixture was stirred at room temperature overnight. The solvent was removed under reduced pressure and the crude product dissolved in ethyl acetate $(100 \mathrm{~mL})$. Organic phase was successively washed with 
saturated aqueous $\mathrm{NaHCO}_{3}$ solution $(100 \mathrm{~mL})$ and brine $(100 \mathrm{~mL})$, dried over $\mathrm{Na}_{2} \mathrm{SO}_{4}$, filtered, and the solvent removed under reduced pressure. Product was used in the next step without further purification. Yield: $1.655 \mathrm{~g}(100 \%)$; yellow solid; $\mathrm{mp} 128-130^{\circ} \mathrm{C}$; ${ }^{1} \mathrm{H}$ NMR (400 MHz, DMSO- $\left.d_{6}\right): \delta 1.18\left(\mathrm{t}, 3 \mathrm{H}, J=7.1 \mathrm{~Hz}, \mathrm{CH}_{2} \mathrm{CH}_{3}\right), 1.48$ (s, 9H, C(CH $\left.)_{3}\right), 3.64$ (d, $\left.2 \mathrm{H}, J=0.7 \mathrm{~Hz}, \mathrm{CH}_{2}\right), 4.07$ (q, $2 \mathrm{H}, J=7.1 \mathrm{~Hz}$, $\mathrm{OCH}_{2} \mathrm{CH}_{3}$ ), 6.92 (s, 1H, Ar-H), 11.44 (br s, 1H, NHCO) ppm; MS (ESI-) $\mathrm{m} / \mathrm{z}$ for $\mathrm{C}_{12} \mathrm{H}_{17} \mathrm{~N}_{2} \mathrm{O}_{4} \mathrm{~S}\left([\mathrm{M}-\mathrm{H}]^{-}\right)$: 285 (100).

\section{Ethyl 2-(2-acetamidothiazol-4-yl)acetate (18)}

A solution of $16(1.066 \mathrm{~g}, 5.73 \mathrm{mmol})$ and triethylamine $(1.040 \mathrm{~mL}$, $7.46 \mathrm{mmol}$ ) in dichloromethane $(50 \mathrm{~mL})$ was cooled to $0^{\circ} \mathrm{C}$ on an ice bath under an argon atmosphere. Then acetyl chloride $(0.450 \mathrm{~mL}$, $6.33 \mathrm{mmol}$ ) was added dropwise. The reaction mixture was stirred at room temperature for $4 \mathrm{~h}$. Organic phase was successively washed with $10 \%$ citric acid $(2 \times 20 \mathrm{~mL})$, saturated aqueous $\mathrm{NaHCO}_{3}$ solution $(2 \times 20 \mathrm{~mL})$ and brine $(20 \mathrm{~mL})$, dried over $\mathrm{Na}_{2} \mathrm{SO}_{4}$, filtered and the solvent removed under reduced pressure. Crude product was crystallized from a mixture of ethyl acetate/hexane (1:2). Yield: $0.591 \mathrm{~g}(45.3 \%) ;$ yellow solid; mp $112-114^{\circ} \mathrm{C} ;{ }^{1} \mathrm{H}$ NMR $(400 \mathrm{MHz}$, DMSO- $d_{6}$ ): $\delta 1.18$ (t, $3 \mathrm{H}, J=7.1 \mathrm{~Hz}, \mathrm{CH}_{2} \mathrm{CH}_{3}$ ), 2.12 (s, 3H, $\mathrm{COCH}_{3}$ ), 3.68 (s, $2 \mathrm{H}, \mathrm{CH}_{2}$ ), 4.08 (q, $2 \mathrm{H}, J=7.1 \mathrm{~Hz}, \mathrm{OCH}_{2} \mathrm{CH}_{3}$ ), 6.95 (s, $1 \mathrm{H}, \mathrm{Ar}-\mathrm{H}$ ), 12.14 (br s, $1 \mathrm{H}, \mathrm{NHCO}$ ) ppm; ${ }^{13} \mathrm{C}$ NMR $\left(100 \mathrm{MHz}\right.$, DMSO-d $\left.d_{6}\right): \delta 14.6$,

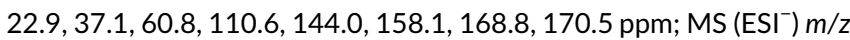
for $\mathrm{C}_{9} \mathrm{H}_{11} \mathrm{~N}_{2} \mathrm{O}_{3} \mathrm{~S}\left([\mathrm{M}-\mathrm{H}]^{-}\right): 227$ (100).

\section{Ethyl 2-(2-(3-ethylureido)thiazol-4-yl)acetate (19)}

A solution of $16(4.214 \mathrm{~g}, 22.7 \mathrm{mmol})$ in chloroform $(100 \mathrm{~mL})$ was cooled to $0^{\circ} \mathrm{C}$ on an ice bath under an argon atmosphere. Then ethyl isocyanate $(2.87 \mathrm{~mL}, 36.2 \mathrm{mmol}$ ) was added dropwise over $20 \mathrm{~min}$. The reaction mixture was stirred at $50^{\circ} \mathrm{C}$ overnight. Reaction mixture was transferred to the separating funnel and successively washed with saturated aqueous $\mathrm{NaHCO}_{3}$ solution $(2 \times 25 \mathrm{~mL})$ and brine $(100 \mathrm{~mL})$, dried over $\mathrm{Na}_{2} \mathrm{SO}_{4}$, filtered and the solvent removed under reduced pressure. Crude product was purified by column chromatography using ethyl acetate $/ n$-hexane (1:6) as eluent. Yield: $2.665 \mathrm{~g}$ (45.8\%); white solid; mp $152-154^{\circ} \mathrm{C} ;{ }^{1} \mathrm{H} \mathrm{NMR}\left(400 \mathrm{MHz}\right.$, DMSO- $\left.d_{6}\right): \delta 1.06$ (t, $3 \mathrm{H}, J=7.2 \mathrm{~Hz}, \mathrm{NHCH}_{2} \mathrm{CH}_{3}$ ), $1.18\left(\mathrm{t}, 3 \mathrm{H}, J=7.1 \mathrm{~Hz}, \mathrm{OCH}_{2} \mathrm{CH}_{3}\right.$ ), 3.09$3.17\left(\mathrm{~m}, 2 \mathrm{H}, \mathrm{NHCH}_{2} \mathrm{CH}_{3}\right), 3.60$ (s, $2 \mathrm{H}, \mathrm{CH}_{2}$ ), 4.08 (q, $2 \mathrm{H}, J=7.1 \mathrm{~Hz}$, $\mathrm{OCH}_{2} \mathrm{CH}_{3}$ ), 6.45 (br s, $1 \mathrm{H}, \mathrm{NHCH}_{2} \mathrm{CH}_{3}$ ), 6.76 (s, 1H, Ar-H), 10.44 (br s, $1 \mathrm{H}, \mathrm{NHCO}) \mathrm{ppm} ;{ }^{13} \mathrm{C} \mathrm{NMR}\left(100 \mathrm{MHz}\right.$, DMSO- $\left.d_{6}\right): \delta 14.5,15.7,34.6$,

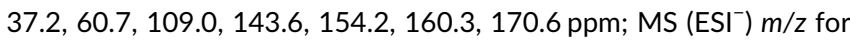
$\mathrm{C}_{10} \mathrm{H}_{14} \mathrm{~N}_{3} \mathrm{O}_{3} \mathrm{~S}\left([\mathrm{M}-\mathrm{H}]^{-}\right): 256(100)$.

\section{2-(2-((tert-Butoxycarbonyl)amino)thiazol-4-yl)acetic acid (20)}

To a solution of $17(1.655 \mathrm{~g}, 5.79 \mathrm{mmol})$ in methanol $(20 \mathrm{~mL}), 2 \mathrm{M}$ $\mathrm{NaOH}(11.6 \mathrm{~mL}, 23.2 \mathrm{mmol})$ was added and the reaction mixture stirred at room temperature overnight. Reaction mixture was then stirred at $50^{\circ} \mathrm{C}$ for additional $2 \mathrm{~h}$. Methanol was evaporated under reduced pressure and reaction mixture extracted with ethyl acetate $(2 \times 20 \mathrm{~mL})$. Water phase was acidified with concentrated $\mathrm{HCl}$ to $\mathrm{pH} \sim 2$. Precipitate was filtered off and dried. Yield: $0.822 \mathrm{~g}$ (55.1\%); yellow solid; mp $160-162^{\circ} \mathrm{C} ;{ }^{1} \mathrm{H}$ NMR (400 MHz, DMSO- $d_{6}$ ): $\delta 1.48$ (s,
9H, $\left.\mathrm{C}\left(\mathrm{CH}_{3}\right)_{3}\right), 3.55$ (s, 2H, CH $\left.\mathrm{CH}_{2}\right), 6.89$ (s, $\left.1 \mathrm{H}, \mathrm{Ar}-\mathrm{H}\right), 11.42$ (br s, $1 \mathrm{H}$, $\mathrm{NHCO}), 12.35$ (s, $1 \mathrm{H}, \mathrm{COOH}) \mathrm{ppm} ;{ }^{13} \mathrm{C}$ NMR (100 MHz, DMSO-d $)^{\text {): } \delta}$ 28.4 (3C), 37.3, 81.5, 110.0, 144.9, 159.7, 159.8, 172.1 ppm; MS (ESI ${ }^{-}$) $\mathrm{m} / \mathrm{z}$ for $\mathrm{C}_{10} \mathrm{H}_{13} \mathrm{~N}_{2} \mathrm{O}_{4} \mathrm{~S}\left([\mathrm{M}-\mathrm{H}]^{-}\right): 257$ (100).

\section{2-(2-Acetamidothiazol-4-yl)acetic acid (21)}

To a solution of $19(0.591 \mathrm{~g}, 2.59 \mathrm{mmol})$ in methanol $(20 \mathrm{~mL}), 2 \mathrm{M}$ $\mathrm{NaOH}(5.2 \mathrm{~mL}, 10.4 \mathrm{mmol}$ ) was added and the reaction mixture stirred at room temperature overnight. Reaction mixture was then stirred at $50^{\circ} \mathrm{C}$ for additional $2 \mathrm{~h}$. Methanol was evaporated under reduced pressure and reaction mixture extracted with ethyl acetate $(2 \times 20 \mathrm{~mL})$. Water phase was acidified with concentrated $\mathrm{HCl}$ to $\mathrm{pH} \sim 2$. Water phase was extracted with ethyl acetate $(3 \times 50 \mathrm{~mL})$, combined organic phases washed with brine $(100 \mathrm{~mL})$, dried over $\mathrm{Na}_{2} \mathrm{SO}_{4}$, filtered and the solvent removed under reduced pressure. Yield: $0.138 \mathrm{~g}(26.6 \%)$; yellowish solid; mp $211-213^{\circ} \mathrm{C} ;{ }^{1} \mathrm{H}$ NMR (400 MHz, DMSO- $\left.d_{6}\right): \delta 2.12$ (s, 3H, $\mathrm{COCH}_{3}$ ), 3.58 (s, $2 \mathrm{H}, \mathrm{CH}_{2}$ ), 6.92 (s, 1H, Ar-H), 12.12 (br s, 1H, $\mathrm{NHCO}$ ), 12.36 (br s, $1 \mathrm{H}, \mathrm{COOH}$ ) ppm; $\left.{ }^{13} \mathrm{C} \mathrm{NMR} \mathrm{(100} \mathrm{MHz,} \mathrm{DMSO-} d_{6}\right)$ : $\delta 22.9,37.3,110.3,144.6,157.9,168.8,172.1 \mathrm{ppm} ; \mathrm{MS}_{\left(\mathrm{ESI}^{+}\right) \mathrm{m} / \mathrm{z} \text { for }}$ $\mathrm{C}_{7} \mathrm{H}_{8} \mathrm{~N}_{2} \mathrm{O}_{3} \mathrm{SNa}\left([\mathrm{M}+\mathrm{Na}]^{+}\right): 223$ (100).

\section{2-(2-(3-Ethylureido)thiazol-4-yl)acetic acid (22)}

To a solution of 19 ( $2.645 \mathrm{~g}, 10.3 \mathrm{mmol})$ in ethanol $(20 \mathrm{~mL}), 2 \mathrm{M} \mathrm{NaOH}$ $(20.6 \mathrm{~mL}, 41.2 \mathrm{mmol})$ was added and the reaction mixture stirred at room temperature overnight. Ethanol was evaporated under reduced pressure and reaction mixture extracted with ethyl acetate $(2 \times 25 \mathrm{~mL})$. Water phase was acidified with concentrated $\mathrm{HCl}$ to $\mathrm{pH} \sim 2$. Precipitate was filtered off and dried. Yield: $2.308 \mathrm{~g}$ (97.9\%); white solid; mp $173-175^{\circ} \mathrm{C} ;{ }^{1} \mathrm{H}$ NMR $\left(400 \mathrm{MHz}\right.$, DMSO-d $\left.d_{6}\right): \delta 1.06(\mathrm{t}, 3 \mathrm{H}$, $J=7.2 \mathrm{~Hz}, \mathrm{NHCH}_{2} \mathrm{CH}_{3}$ ), 3.10-3.17 (m, 2H, NHCH $\left.\mathrm{CH}_{3}\right), 3.51$ (s, $2 \mathrm{H}$, $\mathrm{CH}_{2}$ ), $6.45\left(\mathrm{t}, 1 \mathrm{H}, \mathrm{J}=4.8 \mathrm{~Hz}, \mathrm{NHCH}_{2} \mathrm{CH}_{3}\right), 6.74(\mathrm{~s}, 1 \mathrm{H}, \mathrm{Ar}-\mathrm{H}), 10.41(\mathrm{br}$ $\mathrm{s}, 1 \mathrm{H}, \mathrm{NHCO}$ ), 12.29 (s, $1 \mathrm{H}, \mathrm{COOH}$ ) ppm; ${ }^{13} \mathrm{C} \mathrm{NMR}$ (100 MHz, DMSO$\left.d_{6}\right): \delta 15.2,34.0,36.6,108.4,142.9,153.8,159.6,171.5$ ppm. MS (ESI $\left.{ }^{+}\right)$ $\mathrm{m} / \mathrm{z}$ for $\mathrm{C}_{8} \mathrm{H}_{11} \mathrm{~N}_{3} \mathrm{O}_{3} \mathrm{SNa}\left([\mathrm{M}+\mathrm{Na}]^{+}\right): 252$ (100).

Methyl 3-(2-(2-(3-ethylureido)thiazol-4-yl)acetamido)benzoate (23)

Compound was prepared from $22(0.076 \mathrm{~g}, 0.33 \mathrm{mmol})$ and methyl 3-aminobenzoate $(0.050 \mathrm{~g}, 0.33 \mathrm{mmol})$ according to the general procedure $\mathbf{A}$. Crude product was purified by column chromatography using dichloromethane/methanol (40:1) as eluent. Yield: $0.030 \mathrm{~g}$ (25.0\%); yellow solid; mp $140-142^{\circ} \mathrm{C} ;{ }^{1} \mathrm{H}$ NMR $(400 \mathrm{MHz}$, DMSO$\left.d_{6}\right): \delta 1.05\left(\mathrm{t}, 3 \mathrm{H}, J=7.2 \mathrm{~Hz}, \mathrm{NHCH}_{2} \mathrm{CH}_{3}\right), 3.10-3.17(\mathrm{~m}, 2 \mathrm{H}$, $\mathrm{NHCH}_{2} \mathrm{CH}_{3}$ ), 3.62 (s, $2 \mathrm{H}, \mathrm{CH}_{2}$ ), 3.85 (s, 3H, $\mathrm{COOCH}_{3}$ ), 6.44 (t, $1 \mathrm{H}$, $\left.J=5.2 \mathrm{~Hz}, \mathrm{NHCH}_{2} \mathrm{CH}_{3}\right), 6.78(\mathrm{~s}, 1 \mathrm{H}$, thiazole-H), $7.46(\mathrm{t}, 1 \mathrm{H}$, $J=8.0 \mathrm{~Hz}, \quad \operatorname{Ar}-\mathrm{H}-5$ ), 7.64 (ddd, $1 \mathrm{H}, \quad J_{1}=8.0 \mathrm{~Hz}, J_{2}=2.0 \mathrm{~Hz}$, $J_{3}=1.1 \mathrm{~Hz}, \quad$ Ar-H-4/6), 7.85 (ddd, $1 \mathrm{H}, \quad J_{1}=8.0 \mathrm{~Hz}, \quad J_{2}=2.0 \mathrm{~Hz}$, $\left.J_{3}=1.1 \mathrm{~Hz}, \mathrm{Ar}-\mathrm{H}-4 / 6\right), 8.29(\mathrm{t}, 1 \mathrm{H}, J=2.0 \mathrm{~Hz}, \mathrm{Ar}-\mathrm{H}-2), 10.35$ (s, $1 \mathrm{H}, \mathrm{NHCO}), 10.40$ (s, 1H, NHCO) ppm; ${ }^{13} \mathrm{C}$ NMR (100 MHz, DMSO$\left.d_{6}\right): \delta 15.2,34.1,52.2,108.2,119.5,123.5,123.8,129.2,130.1$, 139.5, 144.4, 153.7, 159.7, 159.8, 166.1, 168.3 ppm; HRMS (ESI ${ }^{-}$) $\mathrm{m} / \mathrm{z}$ for $\mathrm{C}_{16} \mathrm{H}_{17} \mathrm{~N}_{4} \mathrm{O}_{4} \mathrm{~S}\left([\mathrm{M}-\mathrm{H}]^{-}\right)$: calcd. 361.0971, found 361.0975; HPLC: method A, $t_{\mathrm{r}} 11.16 \mathrm{~min}(100 \%$ at $254 \mathrm{~nm})$. 
Methyl 4-(2-(2-(3-ethylureido)thiazol-4-yl)acetamido)benzoate (24) Compound was prepared from $22(0.200 \mathrm{~g}, 0.87 \mathrm{mmol})$ and methyl 4 aminobenzoate $(0.132 \mathrm{~g}, 0.87 \mathrm{mmol})$ according to the general procedure $\mathbf{A}$. Crude product was purified by column chromatography using dichloromethane/methanol (20:1) as eluent. Yield: $0.066 \mathrm{~g}$ (20.9\%); orange solid; mp $122-124^{\circ} \mathrm{C} ;{ }^{1} \mathrm{H}$ NMR (400 MHz, DMSO- $\left.d_{6}\right): \delta 1.04$ (t, $3 \mathrm{H}, J=7.2 \mathrm{~Hz}, \mathrm{NHCH}_{2} \mathrm{CH}_{3}$ ), 3.10-3.16 (m, 2H, $\left.\mathrm{NHCH}_{2} \mathrm{CH}_{3}\right), 3.65$ (s, $2 \mathrm{H}, \mathrm{CH}_{2}$ ), 3.83 (s, 3H, $\mathrm{COOCH}_{3}$ ), $6.43\left(\mathrm{t}, 1 \mathrm{H}, J=5.3 \mathrm{~Hz}, \mathrm{NHCH}_{2} \mathrm{CH}_{3}\right.$ ), $6.78(\mathrm{~s}, 1 \mathrm{H}$, thiazole-H), 7.75 (d, $2 \mathrm{H}, J=8.8 \mathrm{~Hz}, \mathrm{Ar}-\mathrm{H}), 7.92(\mathrm{~d}, 2 \mathrm{H}$, $J=8.8 \mathrm{~Hz}, \mathrm{Ar}-\mathrm{H}$ ), 10.42 (s, 1H, NHCO), 10.48 (s, 1H, NHCO) ppm; ${ }^{13} \mathrm{C}$ NMR (100 MHz, DMSO- $\left.d_{6}\right): \delta 15.2,34.1,51.9,108.3,118.4$ (2C), 123.8, 130.3 (2C), 143.6, 144.2, 153.7, 159.7 (2C), 165.8, 168.6 ppm; HRMS (ESI ${ }^{-}$) $\mathrm{m} / \mathrm{z}$ for $\mathrm{C}_{16} \mathrm{H}_{17} \mathrm{~N}_{4} \mathrm{O}_{4} \mathrm{~S}\left([\mathrm{M}-\mathrm{H}]^{-}\right)$: calcd. 361.0971, found 361.0977; HPLC: method A, $t_{\mathrm{r}} 11.19 \mathrm{~min}$ (100\% at $254 \mathrm{~nm}$ ).

3-(2-(2-(3-Ethylureido)thiazol-4-yl)acetamido)benzoic acid (25) To a solution of $23(0.015 \mathrm{~g}, 0.041 \mathrm{mmol})$ in methanol $(5 \mathrm{~mL}), 2 \mathrm{M}$ $\mathrm{NaOH}(0.062 \mathrm{~mL}, 0.12 \mathrm{mmol})$ was added and the reaction mixture stirred at room temperature overnight. Methanol was evaporated under reduced pressure and water phase acidified with concentrated $\mathrm{HCl}$ to $\mathrm{pH} \sim 2$. Precipitate was filtered off and dried. Yield: $0.012 \mathrm{~g}$ (83.2\%); brown solid; mp $154-156{ }^{\circ} \mathrm{C} ;{ }^{1} \mathrm{H}$ NMR (400 MHz, DMSO- $d_{6}$ ): $\delta 1.04\left(\mathrm{t}, 3 \mathrm{H}, J=7.2 \mathrm{~Hz}, \mathrm{NHCH}_{2} \mathrm{CH}_{3}\right), 3.10-3.16\left(\mathrm{~m}, 2 \mathrm{H}, \mathrm{NHCH}_{2} \mathrm{CH}_{3}\right)$, $3.63\left(\mathrm{~s}, 2 \mathrm{H}, \mathrm{CH}_{2}\right), 6.56\left(\mathrm{t}, 1 \mathrm{H}, J=5.1 \mathrm{~Hz}, \mathrm{NHCH}_{2} \mathrm{CH}_{3}\right), 6.78(\mathrm{~s}, 1 \mathrm{H}$, thiazole-H), $7.43(\mathrm{t}, 1 \mathrm{H}, J=7.9 \mathrm{~Hz}, \mathrm{Ar}-\mathrm{H}-5), 7.62(\mathrm{~d}, 1 \mathrm{H}, J=7.9 \mathrm{~Hz}, \mathrm{Ar}-$ $\mathrm{H}-4 / 6), 7.84$ (d, 1H, J = 7.9 Hz, Ar-H-4/6), 8.25 (s, 1H, Ar-H-2), 10.35 (s, $1 \mathrm{H}, \mathrm{NHCO}$ ), 10,48 (s, 1H, NHCO), 12.97 (br s, 1H, COOH) ppm; ${ }^{13} \mathrm{C}$ NMR $\left(100 \mathrm{MHz}\right.$, DMSO- $\left.d_{6}\right): \delta 15.2,34.1,108.2,119.7,123.1$, 124.0, 129.0, 131.2, 137.9, 139.4, 144.0, 153.6, 159.8, 167.1, $168.2 \mathrm{ppm}$; HRMS $\left(\mathrm{ESI}^{-}\right) \mathrm{m} / \mathrm{z}$ for $\mathrm{C}_{15} \mathrm{H}_{15} \mathrm{~N}_{4} \mathrm{O}_{4} \mathrm{~S}\left([\mathrm{M}-\mathrm{H}]^{-}\right)$: calcd. 347.0814, found 347.0818; HPLC: method $A, t_{r} 9.99 \min (100 \%$ at $254 \mathrm{~nm})$.

4-(2-(2-(3-Ethylureido)thiazol-4-yl)acetamido)benzoic acid (26)

To a solution of $24(0.039 \mathrm{~g}, 0.11 \mathrm{mmol})$ in methanol $(5 \mathrm{~mL}), 2 \mathrm{M} \mathrm{NaOH}$ $(0.16 \mathrm{~mL}, 0.32 \mathrm{mmol})$ was added and the reaction mixture stirred at room temperature overnight. Methanol was evaporated under reduced pressure and water phase acidified with concentrated $\mathrm{HCl}$ to $\mathrm{pH} \sim 2$. Precipitate was filtered off and dried. Yield: $0.028 \mathrm{~g}(74.7 \%)$; yellow solid; mp $248-250{ }^{\circ} \mathrm{C} ;{ }^{1} \mathrm{H}$ NMR $\left(400 \mathrm{MHz}\right.$, DMSO- $\left.d_{6}\right): \delta 1.05(\mathrm{t}$, $3 \mathrm{H}, J=7.2 \mathrm{~Hz}, \mathrm{NHCH}_{2} \mathrm{CH}_{3}$ ), 3.11-3.17 (m, 2H, $\mathrm{NHCH}_{2} \mathrm{CH}_{3}$ ), 3.68 (s, $\left.2 \mathrm{H}, \mathrm{CH}_{2}\right), 6.68\left(\mathrm{t}, 1 \mathrm{H}, \mathrm{J}=5.8 \mathrm{~Hz}, \mathrm{NHCH}_{2} \mathrm{CH}_{3}\right), 6.81$ (s, $1 \mathrm{H}$, thiazole-H), $7.73(\mathrm{~d}, 2 \mathrm{H}, J=8.9 \mathrm{~Hz}, \operatorname{Ar}-\mathrm{H}$ ), 7.89 (d, $2 \mathrm{H}, J=8.9 \mathrm{~Hz}, \operatorname{Ar}-\mathrm{H}$ ), 10.51 (s, $1 \mathrm{H}, \mathrm{NHCO}$ ), 10.61 (br s, $1 \mathrm{H}, \mathrm{NHCO}$ ) ppm; signal for $\mathrm{COOH}$ not seen in the spectrum; ${ }^{13} \mathrm{C}$ NMR $\left(100 \mathrm{MHz}\right.$, DMSO- $\left.d_{6}\right): \delta 15.1,34.2,108.8$, 118.3 (2C), 125.1, 130.4 (2C), 142.2, 143.2, 153.4, 160.3, 166.9, $168.2 \mathrm{ppm}$; HRMS (ESI $\left.{ }^{-}\right) \mathrm{m} / \mathrm{z}$ for $\mathrm{C}_{15} \mathrm{H}_{15} \mathrm{~N}_{4} \mathrm{O}_{4} \mathrm{~S}\left([\mathrm{M}-\mathrm{H}]^{-}\right)$: calcd. 347.0814, found 347.0804; HPLC: method $A, t_{r} 9.91 \mathrm{~min}(100 \%$ at $254 \mathrm{~nm})$.

1-Ethyl-3-(6-nitrobenzo[1,2-d]thiazol-2-yl)urea (28)

To a suspension of $27(4.88 \mathrm{~g}, 25.0 \mathrm{mmol})$ in toluene $(100 \mathrm{~mL})$, triethyl amine (3.49 mL, $25.0 \mathrm{mmol}$ ) and ethyl isocyanate (1.98 mL, $25.0 \mathrm{mmol}$ ) were added and the reaction mixture stirred under reflux overnight. The reaction mixture was then cooled on an ice bath, precipitate filtered off and dried to obtain 28 as a yellow solid. Yield: $5.75 \mathrm{~g}$ (86.0\%); ${ }^{1} \mathrm{H}$ NMR (400 MHz, DMSO- $d_{6}$ ): $\delta 1.10$ (t, $3 \mathrm{H}, J=7.2 \mathrm{~Hz}$, $\left.\mathrm{NHCH}_{2} \mathrm{CH}_{3}\right), \quad 3.17-3.24$ (m, 2H, $\left.\mathrm{NHCH}_{2} \mathrm{CH}_{3}\right), 6.80$ (s, $1 \mathrm{H}$, $\mathrm{NH} \mathrm{CH}_{2} \mathrm{CH}_{3}$ ), 7.74 (d, $\left.1 \mathrm{H}, J=8.9 \mathrm{~Hz}, \quad A r-\mathrm{H}-4\right), 8.21$ (dd, $1 \mathrm{H}$, $\left.J_{1}=8.9 \mathrm{~Hz}, J_{2}=2.5 \mathrm{~Hz}, \operatorname{Ar}-\mathrm{H}-5\right), 8.94(\mathrm{~d}, 1 \mathrm{H}, J=2.5 \mathrm{~Hz}, \operatorname{Ar}-\mathrm{H}-7$ ), 11.20 (s, $1 \mathrm{H}, \mathrm{NHCO}) \mathrm{ppm} ;{ }^{13} \mathrm{C}$ NMR $\left(100 \mathrm{MHz}, \mathrm{DMSO}-d_{6}\right): \delta 15.0$, $34.4,118.5,119.4,121.6,132.2,142.2,153.4,154.3165 .3 \mathrm{ppm}$.

\section{1-(6-Aminobenzo[1,2-d]thiazol-2-yl)-3-ethylurea (29)}

Compound $28(1.512 \mathrm{~g}, 5.68 \mathrm{mmol})$ was dissolved in a mixture of ethanol $(100 \mathrm{~mL}$ ) and $\mathrm{N}, \mathrm{N}$-dimethylformamide $(30 \mathrm{~mL}), \mathrm{Pd}-\mathrm{C}(150 \mathrm{mg})$ was added and the reaction mixture was stirred under hydrogen atmosphere for $48 \mathrm{~h}$. The catalyst was filtered off and the solvent removed under reduced pressure. Crude product was purified by column chromatography using dichloromethane/methanol (20:1) as eluent. Yield: $0.411 \mathrm{~g}$ (30.6\%); brown solid; $\mathrm{mp} 198-200^{\circ} \mathrm{C} ;{ }^{1} \mathrm{H}$ NMR (400 MHz, DMSO- $d_{6}$ ): $\delta 1.07$ (t, $3 \mathrm{H}, J=7.2 \mathrm{~Hz}, \mathrm{NHCH}_{2} \mathrm{CH}_{3}$ ), 3.13$3.20\left(\mathrm{~m}, 2 \mathrm{H}, \mathrm{NHCH}_{2} \mathrm{CH}_{3}\right), 5.03\left(\mathrm{~s}, 2 \mathrm{H}, \mathrm{NH}_{2}\right), 6.63\left(\mathrm{dd}, 1 \mathrm{H}, J_{1}=8.5 \mathrm{~Hz}\right.$, $\left.J_{2}=2.2 \mathrm{~Hz}, \mathrm{Ar}-\mathrm{H}-5\right), 6.68\left(\mathrm{t}, 1 \mathrm{H}, J=5.8 \mathrm{~Hz}, \mathrm{NHCH}_{2} \mathrm{CH}_{3}\right), 6.94(\mathrm{~d}, 1 \mathrm{H}$, $J=2.2 \mathrm{~Hz}, \operatorname{Ar}-\mathrm{H}-7$ ), 7.29 (d, $1 \mathrm{H}, J=8.5 \mathrm{~Hz}, \operatorname{Ar}-\mathrm{H}-4), 10.28$ (s, $1 \mathrm{H}$, $\mathrm{NHCO})$ ppm; $\mathrm{MS}\left(\mathrm{ESI}^{+}\right) \mathrm{m} / \mathrm{z}$ for $\mathrm{C}_{10} \mathrm{H}_{12} \mathrm{~N}_{4} \mathrm{OSNa}\left([\mathrm{M}+\mathrm{Na}]^{+}\right): 259$ (100).

Ethyl 2-((2-(3-ethylureido)benzo[1,2-d]thiazol-6-yl)amino)-2oxoacetate (30)

To a solution of $29(0.100 \mathrm{~g}, 0.42 \mathrm{mmol})$ and $\mathrm{Et}_{3} \mathrm{~N}(0.147 \mathrm{~mL}, 1.1 \mathrm{mmol})$ in 1,4-dioxane $(20 \mathrm{~mL})$, ethyl 2-chloro-2-oxoacetate $(0.057 \mathrm{~mL}$, $0.51 \mathrm{mmol}$ ) was added dropwise under an argon atmosphere. Reaction mixture was stirred at room temperature for $18 \mathrm{~h}$. The precipitate was filtered off, solvent was removed under reduced pressure and the crude product purified by flash column chromatography using dichloromethane/methanol (20:1) as eluent. Yield: $0.015 \mathrm{~g}$ (10.5\%); yellow solid; mp $253-255^{\circ} \mathrm{C} ;{ }^{1} \mathrm{H}$ NMR (400 MHz, DMSO-d $\left.d_{6}\right): \delta 1.10$ (t, $3 \mathrm{H}, J=7.2 \mathrm{~Hz}, \mathrm{NHCH}_{2} \mathrm{CH}_{3}$ ), $1.33\left(\mathrm{t}, 3 \mathrm{H}, J=7.1 \mathrm{~Hz}, \mathrm{COOCH}_{2} \mathrm{CH}_{3}\right.$ ), 3.15-3.22 (m, $\left.2 \mathrm{H}, \mathrm{NHCH}_{2} \mathrm{CH}_{3}\right), 4.32$ (q, $2 \mathrm{H}, J=7.1 \mathrm{~Hz}, \mathrm{COOC}_{2} \mathrm{CH}_{3}$ ), 6.71 (t, $1 \mathrm{H}, J=6.0 \mathrm{~Hz}, \mathrm{NHCH}_{2} \mathrm{CH}_{3}$ ), 7.59 (d, $\left.1 \mathrm{H}, J=8.7 \mathrm{~Hz}, \mathrm{Ar}-\mathrm{H}-4\right)$, $7.67\left(\mathrm{dd}, 1 \mathrm{H}, J_{1}=8.7 \mathrm{~Hz}, J_{2}=1.9 \mathrm{~Hz}, \operatorname{Ar}-\mathrm{H}-5\right), 8.21(\mathrm{~d}, 1 \mathrm{H}, J=1.9 \mathrm{~Hz}$, $\mathrm{Ar}-\mathrm{H}-7$ ), 10.68 (s, 1H, NHCO), 10.88 (s, 1H, NHCO) ppm; ${ }^{13} \mathrm{C}$ NMR $\left(100 \mathrm{MHz}, \mathrm{DMSO}-d_{6}\right): \delta 13.8,15.1,34.2,62.3,113.0,119.3,119.5$, 131.7, 132.5, 145.9, 155.3, 159.6, 160.7, 168.4 ppm; HRMS (ESI $\left.{ }^{-}\right) \mathrm{m} / \mathrm{z}$ for $\mathrm{C}_{14} \mathrm{H}_{15} \mathrm{~N}_{4} \mathrm{O}_{4} \mathrm{~S}\left([\mathrm{M}-\mathrm{H}]^{-}\right)$: calcd. 335.0814, found 335.0810; HPLC: method $A, t_{r} 11.06 \mathrm{~min}(95.9 \%$ at $254 \mathrm{~nm})$.

\section{2-((2-(3-Ethylureido)benzo[1,2-d]thiazol-6-yl)amino)-2-} oxoacetic acid (31)

To a solution of $30(0.010 \mathrm{~g}, 0.030 \mathrm{mmol})$ in methanol $(3 \mathrm{~mL}), 1 \mathrm{M}$ $\mathrm{NaOH}(0.060 \mathrm{~mL}, 0.060 \mathrm{mmol})$ was added and the reaction mixture stirred at room temperature overnight. Then the acidic ion exchange resin Amberlite ${ }^{\circledR}$ IR120 H was added for neutralization ( $\mathrm{pH} \sim 6$ ). After stirring of mixture for $10 \mathrm{~min}$, the resin was filtered off, washed with methanol and the solvent removed in vacuo. Yield: $0.008 \mathrm{~g}(86.9 \%)$; yellow solid; $\mathrm{mp}>300^{\circ} \mathrm{C} ;{ }^{1} \mathrm{H} \mathrm{NMR}\left(400 \mathrm{MHz}, \mathrm{DMSO}-d_{6}\right): \delta 1.09(\mathrm{t}, 3 \mathrm{H}$, 
$\left.J=7.2 \mathrm{~Hz}, \mathrm{NHCH}_{2} \mathrm{CH}_{3}\right), 3.15-3.22\left(\mathrm{~m}, 2 \mathrm{H}, \mathrm{NHCH}_{2} \mathrm{CH}_{3}\right), 6.73(\mathrm{t}, 1 \mathrm{H}$, $J=5.6 \mathrm{~Hz}, \mathrm{NHCH}_{2} \mathrm{CH}_{3}$ ), 7.57 (d, $\left.1 \mathrm{H}, J=8.7 \mathrm{~Hz}, \mathrm{Ar}-\mathrm{H}-4\right), 7.69$ (dd, $1 \mathrm{H}$, $\left.J_{1}=8.7 \mathrm{~Hz}, J_{2}=2.0 \mathrm{~Hz}, \mathrm{Ar}-\mathrm{H}-5\right), 8.31(\mathrm{~d}, 1 \mathrm{H}, J=2.0 \mathrm{~Hz}, \mathrm{Ar}-\mathrm{H}-7), 10.67$ (s, $1 \mathrm{H}, \mathrm{NHCO}), 10.78$ (s, 1H, NHCO) ppm, signal for $\mathrm{COOH}$ not seen in the spectrum; ${ }^{13} \mathrm{C}$ NMR $\left(100 \mathrm{MHz}\right.$, DMSO- $\left.d_{6}\right): \delta 15.1,34.2,112.6$, 116.5, 119.1, 119.4, 125.7, 131.6, 132.8, 159.5, 162.2, $163.3 \mathrm{ppm}$; HRMS (ESI ${ }^{-}$) $\mathrm{m} / \mathrm{z}$ for $\mathrm{C}_{12} \mathrm{H}_{11} \mathrm{~N}_{4} \mathrm{O}_{4} \mathrm{~S}\left([\mathrm{M}-\mathrm{H}]^{-}\right)$: calcd. 307.0501, found 307.0499; HPLC: method A, $t_{\mathrm{r}} 9.36 \mathrm{~min}(100 \%$ at $254 \mathrm{~nm})$.

$\mathrm{N}$-(2-(3-Ethylureido)benzo[1,2- $d$ ]thiazol-6-yl)-2-(2-(3-

ethylureido)thiazol-4-yl)acetamide (32)

Compound was prepared from $22(0.097 \mathrm{~g}, 0.42 \mathrm{mmol})$ and 29 $(0.100 \mathrm{~g}, 0.42 \mathrm{mmol})$ according to the general procedure A. Crude product was crystallized from a mixture of dichloromethane and methanol (20:1). Yield: $0.066 \mathrm{~g}$ (34.7\%); brown solid; $\mathrm{mp} 250-252^{\circ} \mathrm{C}$; ${ }^{1} \mathrm{H}$ NMR (400 MHz, DMSO- $\left.d_{6}\right): \delta 1.05\left(\mathrm{t}, 3 \mathrm{H}, J=7.2 \mathrm{~Hz}, \mathrm{NHCH}_{2} \mathrm{CH}_{3}\right)$, $1.09\left(\mathrm{t}, \quad 3 \mathrm{H}, \quad J=7.2 \mathrm{~Hz}, \quad \mathrm{NHCH}_{2} \mathrm{CH}_{3}\right), \quad 3.10-3.21 \quad(\mathrm{~m}, \quad 4 \mathrm{H}$, $\left.2 \times \mathrm{NHCH}_{2} \mathrm{CH}_{3}\right), 3.62\left(\mathrm{~s}, 2 \mathrm{H}, \mathrm{CH}_{2}\right), 6.45\left(\mathrm{t}, 1 \mathrm{H}, \mathrm{J}=5.4 \mathrm{~Hz}, \mathrm{NHCH}_{2} \mathrm{CH}_{3}\right.$ ), 6.71 (t, $1 \mathrm{H}, J=4.5 \mathrm{~Hz}, \mathrm{NHCH}_{2} \mathrm{CH}_{3}$ ), 6.77 (s, $1 \mathrm{H}$, thiazole-H), 7.46 (dd, $\left.1 \mathrm{H}, J_{1}=8.7 \mathrm{~Hz}, J_{2}=1.9 \mathrm{~Hz}, \mathrm{Ar}-\mathrm{H}-5\right), 7.54(\mathrm{~d}, 1 \mathrm{H}, J=8.7 \mathrm{~Hz}, \mathrm{Ar}-\mathrm{H}-4)$, 8.21 (d, $1 \mathrm{H}, J=1.9 \mathrm{~Hz}, \mathrm{Ar}-\mathrm{H}-7$ ), 10.20 (s, $1 \mathrm{H}, \mathrm{NHCO}$ ), 10.41 (s, $1 \mathrm{H}$, $\mathrm{NHCO}$ ), 10.61 (s, $1 \mathrm{H}, \mathrm{NHCO}) \mathrm{ppm} ;{ }^{13} \mathrm{C} \mathrm{NMR}\left(100 \mathrm{MHz}, \mathrm{DMSO}-d_{6}\right): \delta$ 15.1, 15.2, 34.1, 34.2, 40.1, 108.0, 111.3, 118.0, 119.5, 131.7, 134.4, 144.6, 145.0, 145.1, 153.7, 158.9, 162.3, 167.8 ppm; HRMS $\left(\mathrm{ESI}^{-}\right) \mathrm{m} / \mathrm{z}$ for $\mathrm{C}_{18} \mathrm{H}_{20} \mathrm{~N}_{7} \mathrm{O}_{3} \mathrm{~S}_{2}\left([\mathrm{M}-\mathrm{H}]^{-}\right)$: calcd. 446.1096, found 446.1076; HPLC: method $A, t_{r} 10.44 \min (97.2 \%$ at $254 \mathrm{~nm})$.

tert-Butyl (4-(2-((2-(3-ethylureido)benzo[1,2- $d]$ thiazol-6-yl)amino)-2-oxoethyl)thiazol-2-yl)carbamate (33)

Compound was prepared from $20(0.108 \mathrm{~g}, 0.42 \mathrm{mmol})$ and 29 $(0.100 \mathrm{~g}, 0.42 \mathrm{mmol})$ according to the general procedure A. Crude product was crystallized from a mixture of dichloromethane and methanol (20:1). Yield: $0.085 \mathrm{~g}$ (42.1\%); yellow solid; $\mathrm{mp} 172-174^{\circ} \mathrm{C}$; ${ }^{1} \mathrm{H} \quad \mathrm{NMR} \quad\left(400 \mathrm{MHz}, \quad\right.$ DMSO- $\left.d_{6}\right): \delta 1.09$ (t, $3 \mathrm{H}, \quad J=7.2 \mathrm{~Hz}$, $\left.\mathrm{NHCH}_{2} \mathrm{CH}_{3}\right), 1.48\left(\mathrm{~s}, 9 \mathrm{H}, \mathrm{C}\left(\mathrm{CH}_{3}\right)_{3}\right), 3.15-3.22\left(\mathrm{~m}, 2 \mathrm{H}, \mathrm{NHCH}_{2} \mathrm{CH}_{3}\right)$, 3.66 (s, $2 \mathrm{H}, \mathrm{CH}_{2}$ ), 6.73 (t, $1 \mathrm{H}, J=4.7 \mathrm{~Hz}, \mathrm{NHCH}_{2} \mathrm{CH}_{3}$ ), 6.92 (s, $1 \mathrm{H}$, thiazole-H), 7.46 (dd, $\left.1 \mathrm{H}, J_{1}=8.7 \mathrm{~Hz}, J_{2}=2.0 \mathrm{~Hz}, \mathrm{Ar}-\mathrm{H}-5\right), 7.54(\mathrm{~d}$, $1 \mathrm{H}, J=8.7 \mathrm{~Hz}, \mathrm{Ar}-\mathrm{H}-4), 8.20$ (d, $1 \mathrm{H}, J=2.0 \mathrm{~Hz}, \mathrm{Ar}-\mathrm{H}-7), 10.21$ (s, $1 \mathrm{H}$, $\mathrm{NHCO}$ ), 10.63 (s, 1H, NHCO), 11.44 (s, 1H, NHCO) ppm; ${ }^{13} \mathrm{C}$ NMR $\left(100 \mathrm{MHz}, \mathrm{DMSO}-d_{6}\right): \delta 15.1,27.9$ (3C), 34.2, 40.4, 80.9, 109.3, 111.3, 118.0, 119.5, 131.7, 134.4, 145.1, 145.2, 152.8, 153.7, 158.9, 159.3, $167.7 \mathrm{ppm}$; HRMS (ESI $\left.{ }^{-}\right) \mathrm{m} / \mathrm{z}$ for $\mathrm{C}_{20} \mathrm{H}_{23} \mathrm{~N}_{6} \mathrm{O}_{4} \mathrm{~S}_{2}\left([\mathrm{M}-\mathrm{H}]^{-}\right)$: calcd. 475.1222, found 475.1213. HPLC: method A, $t_{r} 10.54 \mathrm{~min}$ (96.1\% at $254 \mathrm{~nm})$.

2-(2-Acetamidothiazol-4-yl)-N-(2-(3-ethylureido)benzo[1,2-d]thiazol-6-yl)acetamide (34)

Compound was prepared from $21(0.077 \mathrm{~g}, 0.39 \mathrm{mmol})$ and 29 $(0.091 \mathrm{~g}, 0.39 \mathrm{mmol})$ according to the general procedure A. Crude product was crystallized from a mixture of dichloromethane and methanol (20:1). Yield: $0.043 \mathrm{~g}$ (26.7\%); yellow solid; $\mathrm{mp} 263-265^{\circ} \mathrm{C}$; ${ }^{1} \mathrm{H}$ NMR (400 MHz, DMSO- $d_{6}$ ): $\delta 1.09$ (t, 3H, J = 7.2 Hz, $\mathrm{NHCH}_{2} \mathrm{CH}_{3}$ ), $2.11\left(\mathrm{~s}, 3 \mathrm{H}, \mathrm{COCH}_{3}\right), 3.15-3.21\left(\mathrm{~m}, 2 \mathrm{H}, \mathrm{NHCH}_{2} \mathrm{CH}_{3}\right), 3.70\left(\mathrm{~s}, 2 \mathrm{H}, \mathrm{CH}_{2}\right)$, $6.70\left(\mathrm{t}, 1 \mathrm{H}, J=5.0 \mathrm{~Hz}, \mathrm{NHCH}_{2} \mathrm{CH}_{3}\right), 6.95$ (s, $1 \mathrm{H}$, thiazole-H), 7.46 (dd, $\left.1 \mathrm{H}, J_{1}=8.7 \mathrm{~Hz}, J_{2}=2.0 \mathrm{~Hz}, \mathrm{Ar}-\mathrm{H}-5\right), 7.54(\mathrm{~d}, 1 \mathrm{H}, J=8.7 \mathrm{~Hz}, \mathrm{Ar}-\mathrm{H}-4)$, 8.20 (d, $1 \mathrm{H}, J=2.0 \mathrm{~Hz}, \mathrm{Ar}-\mathrm{H}-7$ ), 10.23 (s, $1 \mathrm{H}, \mathrm{NHCO}$ ), 10.63 (s, 1H, $\mathrm{NHCO}$ ), 12.11 (s, 1H, NHCO) ppm; ${ }^{13} \mathrm{C}$ NMR (100 MHz, DMSO-d $)_{6}: \delta$ 15.1, 22.4, 34.2, 40.1, 109.7, 111.3, 118.0, 119.5, 131.8, 134.4, 145.0, 145.2, 153.6, 157.6, 158.9, 167.7, 168.3 ppm; HRMS (ESI ${ }^{-}$) $\mathrm{m} / \mathrm{z}$ for $\mathrm{C}_{17} \mathrm{H}_{17} \mathrm{~N}_{6} \mathrm{O}_{3} \mathrm{~S}_{2}\left([\mathrm{M}-\mathrm{H}]^{-}\right)$: calcd. 417.0804, found 417.0797; HPLC: method $A, t_{r} 10.40 \mathrm{~min}(100 \%$ at $254 \mathrm{~nm})$.

2-(2-Aminothiazol-4-yl)-N-(2-(3-ethylureido)benzo[1,2-d]thiazol-6-yl)acetamide (35)

Methanol $(10 \mathrm{~mL})$ was cooled on an ice bath and then acetyl chloride $(0.860 \mathrm{~mL}, 12.1 \mathrm{mmol})$ was added dropwise. The mixture was stirred at $0^{\circ} \mathrm{C}$ for $30 \mathrm{~min}$ and then solution of $33(0.192 \mathrm{~g}, 0.40 \mathrm{mmol})$ in methanol $(5 \mathrm{~mL})$ was added. Reaction mixture was stirred at $0^{\circ} \mathrm{C}$ for $1 \mathrm{~h}$ and then at room temperature overnight. Then solvent was evaporated under reduced pressure and crude product dissolved in water $(5 \mathrm{~mL})$. Water phase was extracted with ethyl acetate $(3 \times 20 \mathrm{~mL})$, combined organic phases washed with brine $(30 \mathrm{~mL})$, dried over $\mathrm{Na}_{2} \mathrm{SO}_{4}$, filtered and the solvent removed under reduced pressure. Yield: $0.130 \mathrm{~g}$ (86.7\%); yellow solid; mp $135-137^{\circ} \mathrm{C} ;{ }^{1} \mathrm{H}$ NMR (400 MHz, DMSO- $\left.d_{6}\right)$ : $\delta 1.08\left(\mathrm{t}, 3 \mathrm{H}, J=7.2 \mathrm{~Hz}, \mathrm{NHCH}_{2} \mathrm{CH}_{3}\right), 3.13-3.20\left(\mathrm{~m}, 2 \mathrm{H}, \mathrm{NHCH}_{2} \mathrm{CH}_{3}\right)$, $3.60\left(\mathrm{~s}, 2 \mathrm{H}, \mathrm{CH}_{2}\right), 5.03\left(\mathrm{~s}, 2 \mathrm{H}, \mathrm{NH}_{2}\right), 6.63\left(\mathrm{dd}, 1 \mathrm{H}, J_{1}=8.6 \mathrm{~Hz}\right.$, $\left.J_{2}=2.2 \mathrm{~Hz}, \mathrm{Ar}-\mathrm{H}-5\right), 6.68\left(\mathrm{t}, 1 \mathrm{H}, J=5.6 \mathrm{~Hz}, \mathrm{NHCH}_{2} \mathrm{CH}_{3}\right), 6.92(\mathrm{~s}, 1 \mathrm{H}$, thiazole-H), 6.94 (d, $1 \mathrm{H}, J=2.2 \mathrm{~Hz}, \mathrm{Ar}-\mathrm{H}-7), 7.28(\mathrm{~d}, 1 \mathrm{H}, J=8.6 \mathrm{~Hz}, \mathrm{Ar}-$ $\mathrm{H}-4), 10.28$ (s, 1H, NHCO) ppm, signal for $\mathrm{NHCO}$ not seen in the spectrum; HRMS (ESI ${ }^{-}$) $\mathrm{m} / \mathrm{z}$ for $\mathrm{C}_{15} \mathrm{H}_{16} \mathrm{~N}_{6} \mathrm{O}_{2} \mathrm{~S}_{2}\left([\mathrm{M}-\mathrm{H}]^{-}\right)$: calcd. 375.0698, found 375.0691; HPLC: method $A, t_{r} 10.05 \min (98.2 \%$ at $254 \mathrm{~nm}$ ).

Methyl 3-((4-(2-((2-(3-ethylureido)benzo[1,2- $d]$ thiazol-6-yl)amino)-2-oxoethyl)thiazol-2-yl)amino)-3-oxopropanoate (36) A solution of $35(0.100 \mathrm{~g}, 0.27 \mathrm{mmol})$ and triethylamine $(0.092 \mathrm{~mL}$, $0.67 \mathrm{mmol})$ in 1,4-dioxane $(10 \mathrm{~mL})$ was cooled to $0^{\circ} \mathrm{C}$ on an ice bath under an argon atmosphere. Then methyl 3-chloro-3-oxopropanoate $(0.035 \mathrm{~mL}, 0.32 \mathrm{mmol})$ was added dropwise. The reaction mixture was stirred at room temperature overnight. Then solvent was evaporated under reduced pressure and the residue dissolved in ethyl acetate $(20 \mathrm{~mL})$. Organic phase was successively washed with $1 \%$ citric acid $(2 \times 10 \mathrm{~mL})$, saturated aqueous $\mathrm{NaHCO}_{3}$ solution $(2 \times 10 \mathrm{~mL})$ and brine $(10 \mathrm{~mL})$, dried over $\mathrm{Na}_{2} \mathrm{SO}_{4}$, filtered and the solvent removed under reduced pressure. Crude product purified by flash column chromatography using dichloromethane/methanol (20:1) as eluent. Yield: $0.016 \mathrm{~g}$ (12.6\%); yellow solid; mp 129$131^{\circ} \mathrm{C} ;{ }^{1} \mathrm{H}$ NMR $\left(400 \mathrm{MHz}, \mathrm{MeOD}-d_{4}\right): \delta 1.23$ (t, $3 \mathrm{H}, J=7.2 \mathrm{~Hz}$, $\mathrm{NHCH}_{2} \mathrm{CH}_{3}$ ), 3.31-3.33 (m, $2 \mathrm{H}, \mathrm{NHCH}_{2} \mathrm{CH}_{3}$; signal partially overlapped with solvent residual peak), $3.74\left(\mathrm{~s}, 3 \mathrm{H}, \mathrm{CH}_{3}\right), 3.77(\mathrm{~s}, 2 \mathrm{H}$, $\mathrm{CH}_{2}$ ), $3.80\left(\mathrm{~s}, 2 \mathrm{H}, \mathrm{CH}_{2}\right), 7.00(\mathrm{~s}, 1 \mathrm{H}$, thiazole- $\mathrm{H}), 7.45$ (dd, $1 \mathrm{H}$, $\left.J_{1}=8.7 \mathrm{~Hz}, J_{2}=2.1 \mathrm{~Hz}, \mathrm{Ar}-\mathrm{H}-5\right), 7.59$ (d, $\left.1 \mathrm{H}, J=8.7 \mathrm{~Hz}, \mathrm{Ar}-\mathrm{H}-4\right), 7.28$ (d, $1 \mathrm{H}, J=2.1 \mathrm{~Hz}, \mathrm{Ar}-\mathrm{H}-7$ ) ppm, signals for $\mathrm{NH}$ groups not seen in the spectrum; HRMS $\left(\mathrm{ESI}^{+}\right) \mathrm{m} / \mathrm{z}$ for $\mathrm{C}_{19} \mathrm{H}_{21} \mathrm{~N}_{6} \mathrm{O}_{5} \mathrm{~S}_{2}\left([\mathrm{M}+\mathrm{H}]^{+}\right)$: calcd. 477.1015, found 477.1026; HPLC: method $A, t_{r} 10.76 \min (100 \%$ at $254 \mathrm{~nm}$ ). 
Ethyl 2-((4-(2-((2-(3-ethylureido)benzo[1,2-d]thiazol-6-yl)amino)-2-oxoethyl)thiazol-2-yl)amino)-2-oxoacetate (37) A solution of $35(0.200 \mathrm{~g}, 0.53 \mathrm{mmol})$ and triethylamine $(0.185 \mathrm{~mL}$, $1.33 \mathrm{mmol})$ in 1,4 -dioxane $(20 \mathrm{~mL})$ was cooled to $0^{\circ} \mathrm{C}$ on an ice bath under an argon atmosphere. Then ethyl 2-chloro-2-oxoacetate $(0.071 \mathrm{~mL}, 0.64 \mathrm{mmol})$ was added dropwise. The reaction mixture was stirred at room temperature overnight. Then solvent was evaporated under reduced pressure and crude product purified by flash column chromatography using dichloromethane/methanol (30:1) as eluent. Yield: $0.048 \mathrm{~g}$ (19.0\%); yellow solid; mp 141$143^{\circ} \mathrm{C}$; ${ }^{1} \mathrm{H}$ NMR $(400 \mathrm{MHz}$, DMSO-d $\left.)\right): \delta 1.09$ (t, $3 \mathrm{H}, J=7.2 \mathrm{~Hz}$, $\left.\mathrm{NHCH}_{2} \mathrm{CH}_{3}\right), 1.31\left(\mathrm{t}, 3 \mathrm{H}, J=7.1 \mathrm{~Hz}, \mathrm{COOCH}_{2} \mathrm{CH}_{3}\right), 3.15-3.22(\mathrm{~m}$, $\left.2 \mathrm{H}, \mathrm{NHCH}_{2} \mathrm{CH}_{3}\right), 3.77$ (s, $\left.2 \mathrm{H}, \mathrm{CH}_{2}\right), 4.30$ (q, $2 \mathrm{H}, J=7.1 \mathrm{~Hz}$, $\mathrm{COOCH}_{2} \mathrm{CH}_{3}$ ), $6.70\left(\mathrm{t}, 1 \mathrm{H}, J=4.9 \mathrm{~Hz}, \mathrm{NHCH}_{2} \mathrm{CH}_{3}\right), 7.16(\mathrm{~s}, 1 \mathrm{H}$, thiazole-H), 7.47 (dd, $\left.1 \mathrm{H}, J_{1}=8.7 \mathrm{~Hz}, J_{2}=2.0 \mathrm{~Hz}, \mathrm{Ar}-\mathrm{H}-5\right), 7.55(\mathrm{~d}$, $1 \mathrm{H}, J=8.7 \mathrm{~Hz}, \mathrm{Ar}-\mathrm{H}-4), 7.28$ (d, $1 \mathrm{H}, J=2.0 \mathrm{~Hz}, \mathrm{Ar}-\mathrm{H}-7), 10.25$ (s, $1 \mathrm{H}$, $\mathrm{NHCO}$ ), 10.63 (s, 1H, NHCO), 12.99 (s, $1 \mathrm{H}, \mathrm{NHCO}$ ) ppm; ${ }^{13} \mathrm{C} \mathrm{NMR}$ (100 MHz, DMSO- $\left.d_{6}\right): \delta$ 13.7, 15.1, 34.2, 40.1, 62.5, 111.4, 111.7, 118.1, 119.5, 131.8, 134.3, 145.2, 145.7, 153.6, 158.9, 167.4, 167.5, 175.1, 179.6 ppm; HRMS $\left(\mathrm{ESI}^{+}\right) \mathrm{m} / \mathrm{z}$ for $\mathrm{C}_{19} \mathrm{H}_{21} \mathrm{~N}_{6} \mathrm{O}_{5} \mathrm{~S}_{2}\left([\mathrm{M}+\mathrm{H}]^{+}\right)$: calcd. 477.1015, found 477.1009; HPLC: method A, $t_{r} 11.25 \mathrm{~min}$ (95.1\% at $254 \mathrm{~nm})$.

2-((4-(2-((2-(3-Ethylureido)benzo[1,2-d]thiazol-6-yl)amino)-2oxoethyl)thiazol-2-yl)amino)-2-oxoacetic acid (38)

To a solution of $37(0.025 \mathrm{~g}, 0.053 \mathrm{mmol})$ in methanol $(5 \mathrm{~mL}), 1 \mathrm{M}$ $\mathrm{NaOH}(0.11 \mathrm{~mL}, 0.11 \mathrm{mmol})$ was added and the reaction mixture stirred at room temperature overnight. Then the acidic ion exchange resin Amberlite ${ }^{\circledR}$ IR120 H was added for neutralization ( $\mathrm{pH} \sim 6$ ). After stirring of mixture for $10 \mathrm{~min}$, the resin was filtered off, washed with methanol and the solvent removed in vacuo. Yield: $0.017 \mathrm{~g}(72.3 \%)$; orange solid; $\mathrm{mp}>300{ }^{\circ} \mathrm{C} ;{ }^{1} \mathrm{H} \mathrm{NMR}\left(400 \mathrm{MHz}, \mathrm{DMSO}-d_{6}\right): \delta 1.06(\mathrm{t}, 3 \mathrm{H}$, $\left.J=7.2 \mathrm{~Hz}, \mathrm{NHCH}_{2} \mathrm{CH}_{3}\right), 3.10-3.17\left(\mathrm{~m}, 2 \mathrm{H}, \mathrm{NHCH}_{2} \mathrm{CH}_{3}\right), 3.68(\mathrm{~s}, 2 \mathrm{H}$, $\mathrm{CH}_{2}$ ), 6.96 (s, $1 \mathrm{H}$, thiazole-H), 7.19 (br s, $1 \mathrm{H}, \mathrm{NHCH}_{2} \mathrm{CH}_{3}$ ), 7.28-7.37 (m, 2H, Ar-H-4, Ar-H-5), 8.03 (s, 1H, Ar-H-7), 10.11 (s, 1H, NHCO) ppm; signals for $\mathrm{NH}$ groups are not seen in the spectrum; ${ }^{13} \mathrm{CNMR}$ $\left(100 \mathrm{MHz}\right.$, DMSO- $\left.d_{6}\right): \delta 15.2,34.2,40.1,109.8,111.5,118.0,119.5$, $131.8,135.4,145.1,145.5,152.8,156.5,159.8,164.6,167.6$, $170.5 \mathrm{ppm}$; HRMS $\left(\mathrm{ESI}^{+}\right) \mathrm{m} / \mathrm{z}$ for $\mathrm{C}_{17} \mathrm{H}_{15} \mathrm{~N}_{6} \mathrm{O}_{5} \mathrm{~S}_{2}\left([\mathrm{M}-\mathrm{H}]^{-}\right)$: calcd. 447.0545, found 447.0532; HPLC: method $A, t_{r} 9.64 \min (95.2 \%$ at $254 \mathrm{~nm})$.

\section{2 | Molecular modeling}

\subsubsection{Ligand and protein preparation}

Three-dimensional models of designed compounds were built in ChemBio3D Ultra 13.0. ${ }^{[30]}$ Their geometries were optimized using MMFF94 ${ }^{[31]}$ force field and partial atomic charges were added. Energy was minimized until the gradient value was smaller than $0.001 \mathrm{kcal} /(\mathrm{mol} \AA)$. The optimized structure was further refined with GAMESS interface in ChemBio3D Ultra 13.0 using the semiempirical PM3 method, QA optimization algorithm and Gasteiger Hückel charges for all atoms for 100 steps. $^{[30]}$ Molecular docking calculations were performed using Flex $X,{ }^{[32,33]}$ as available in LeadIT ${ }^{\left[{ }^{[4]}\right.}$ running on four octal core AMD Opteron CPU processors, 16 GB RAM, two 750 GB hard drives, running 64-bit Scientific Linux 6.0. Receptor was prepared in a LeadIT graphical user interface using the Receptor wizard. Amino acid residues within a radius of $7 \AA$ around the ligand from the $X$-ray structure (PDB entry: 4DUH ${ }^{[29]}$ ) were defined as the binding site. Hydrogen atoms were added to the binding site residues and correct tautomers and protonation states were assigned. Water molecules, except $\mathrm{HOH} 614$, and the ligand were deleted from the crystal structure.

The FlexX molecular docking program, as available in LeadIT, ${ }^{[34]}$ was used for ligand docking. A hybrid algorithm (enthalpy and entropy driven ligand binding) was used to place the "base fragment". The maximum number of solutions per iteration and the maximum number of solutions per fragmentation parameter values were increased to 1000 , while other parameters were set at their default values. In order to validate our docking protocol, crystal structure ligand was docked into the defined ATP-binding site of E. coli GyrB using the above described docking parameters. The protocol was able to reproduce the binding of the crystal structure ligand with an RMSD value of $1.2 \AA$, which highlights the docking protocol as suitable for binding mode studies of the designed DNA gyrase inhibitors that were docked using the same settings as used for docking protocol validation. Proposed binding modes and scoring function scores of the top five highest scored docking poses per ligand were evaluated and the highest ranked binding pose was used for graphical representation in PyMOL. ${ }^{[35]}$

\section{3 | Biological activity assays}

\subsubsection{In vitro inhibitory activity screening and determination of $I_{50}$ values on E. coli DNA gyrase}

The assay for determining $I C_{50}$ values (Inspiralis) was performed on black streptavidin-coated 96-well microtiter plates (Thermo Scientific Pierce). The plate was first rehydrated with the wash buffer supplied (20 mM Tris- $\mathrm{HCl}$ (pH 7.6), $137 \mathrm{mM} \mathrm{NaCl}, 0.01 \%$ (w/v) BSA, $0.05 \%(v / v)$ Tween 20). Biotinylated oligonucleotide in wash buffer was immobilized onto the wells. The excess of oligonucleotide was then washed off and the enzyme assay carried out in the wells ( $5 \mathrm{~min}$ ). The final reaction volume of $30 \mu \mathrm{L}$ in buffer $(35 \mathrm{mM}$ Tris$\mathrm{HCl}(\mathrm{pH} \mathrm{7.5);2} 2 \mathrm{mM} \mathrm{KCl} ; 4 \mathrm{mM} \mathrm{MgCl} 2 ; 2 \mathrm{mM}$ DTT; $1.8 \mathrm{mM}$ spermidine; $1 \mathrm{mM}$ ATP; $6.5 \%$ (w/v) glycerol; $0.1 \mathrm{mg} / \mathrm{mL}$ albumin) contained $1.5 \mathrm{U}$ of DNA gyrase from E. coli, $0.75 \mu \mathrm{g}$ of relaxed pNO1 plasmid, and $3 \mu \mathrm{L}$ of inhibitors solution in 10\% DMSO and $0.008 \%$ Tween ${ }^{\circledR}$ 20. Reactions were incubated for $30 \mathrm{~min}$ at $37^{\circ} \mathrm{C}$ and, after addition of the TF buffer ( $50 \mathrm{mM} \mathrm{NaOAc}(\mathrm{pH} 5.0$ ), $50 \mathrm{mM} \mathrm{NaCl}$ and $50 \mathrm{mM} \mathrm{MgCl}_{2}$ ), which terminated the enzymatic reaction, for another $30 \mathrm{~min}$ at room temperature to allow triplex formation (biotin-oligonucleotide-plasmid). The unbound plasmid was then washed off using TF buffer, and a solution of SybrGOLD stain in T10 buffer (10 mM Tris- $\mathrm{HCl}$ (pH 8.0) and $1 \mathrm{mM}$ EDTA) was 
added. After mixing, the fluorescence (excitation, $485 \mathrm{~nm}$; emission, $535 \mathrm{~nm}$ ) was read using a BioTek Synergy H4 microplate reader. Preliminary screening was performed at inhibitor concentrations of 100 and $10 \mu \mathrm{M}$. For the most potent compounds, $I_{50}$ was determined with seven concentrations of the inhibitors. $I C_{50}$ values were calculated using GraphPad Prism software and represent the concentration of inhibitor where the residual activity of the enzyme is $50 \%$ in three independent measurements; the final result is given as their average value. Novobiocin $\left(\mathrm{IC}_{50}=0.17 \mu \mathrm{M}\right)$ was used as a positive control.

\subsection{2 | Determination of antibacterial activity}

Clinical control strains of E. faecalis (Gram positive, ATCC 29212), S. aureus (Gram positive, ATCC 25923), E. coli (Gram negative, ATCC 25922), and $P$. aeruginosa (Gram negative, ATCC 27853), were obtained from Microbiologics Inc. (St. Cloud, Minnesota, USA). Single-gene knock-out mutant strains of E. coli, JW5503 (tolC knockout ${ }^{[36]}$ and JD17464 (IpxC knock-out), were obtained from the NBRP-E.coli collection at National Institute of Genetics (NIG, Japan). Antimicrobial testing was carried out by using the broth microdilution method in 96-well plate format according to the CLSI guidelines. ${ }^{[37]}$ Briefly, bacterial suspensions yielding final inoculum of $5 \times 10^{5} \mathrm{CFU} / \mathrm{mL}$ were prepared into cation-adjusted Mueller Hinton broth (Becton Dickinson, Franklin Lakes, NJ, USA) and mixed on the plate with test compound solution diluted into assay media. After incubating the plate for $24 \mathrm{~h}$ at $37^{\circ} \mathrm{C}$, absorbance values were measured at $620 \mathrm{~nm}$ and used for evaluating the antimicrobial effects of test compounds by comparing to untreated controls and expressed as percentage inhibition of growth. Ciprofloxacin was used as a positive control on every assay plate (minimum inhibitory concentration $[\mathrm{MIC}]$ against E. faecalis, S. aureus, E. coli, and $P$. aeruginosa, was $3.0,1.5,0.05$, and $3.0 \mu \mathrm{M}$, respectively). All compounds were initially assayed at final concentration of $50 \mu \mathrm{M}$ $(n=3)$. For compound 33 that displayed $\geq 80 \%$ inhibition at $50 \mu \mathrm{M}$, MIC (lowest concentration that inhibited the growth by $\geq 90 \%$ ) was determined by carrying out dose-response experiments at eight different concentrations.

\section{ACKNOWLEDGMENTS}

This work was supported by the Slovenian Research Agency (Grant No. P1-0208), by the Marie Skłodowska-Curie ETN INTEGRATE (Contract No. 642620), and by the Academy of Finland (Grant No. 277001 and 284477). The authors thank Dr. Dušan Žigon (Mass Spectrometry Center, Jožef Stefan Institute, Ljubljana, Slovenia) for recording mass spectra, and Heidi Mäkkylä for technical assistance in the antibacterial assays. The authors thank Christopher Berrie for proofreading the manuscript.

\section{CONFLICT OF INTEREST}

The authors have declared no conflict of interest.

\section{ORCID}

Tihomir Tomašič (iD http://orcid.org/0000-0001-5534-209X

\section{REFERENCES}

[1] R. Tommasi, D. G. Brown, G. K. Walkup, J. I. Manchester, A. A. Miller, Nat. Rev. Drug Discov. 2015, 14, 529.

[2] J. J. Champoux, Annu. Rev. Biochem. 2001, 70, 369.

[3] G. S. Bisacchi, J. I. Manchester, ACS Infect. Dis. 2015, 1, 4.

[4] C. Mayer, Y. L. Janin, Chem. Rev. 2014, 114, 2313.

[5] T. Tomašič, L. Peterlin Mašič, Curr. Top. Med. Chem. 2014, 14, 130.

[6] P. Angehrn, E. Goetschi, H. Gmuender, P. Hebeisen, M. Hennig, B. Kuhn, T. Luebbers, P. Reindl, F. Ricklin, A. Schmitt-Hoffmann, J. Med. Chem. 2011, 54, 2207.

[7] A. L. Grillot, A. Le Tiran, D. Shannon, E. Krueger, Y. Liao, H. O'Dowd, Q Tang, S. Ronkin, T. Wang, N. Waal, P. Li, D. Lauffer, E. Sizensky, J. Tanoury, E. Perola, T. H. Grossman, T. Doyle, B. Hanzelka, S. Jones, V. Dixit, N. Ewing, S. Liao, B. Boucher, M. Jacobs, Y. Bennani, P. S. Charifson, J. Med. Chem. 2014, 57, 8792.

[8] J. T. Starr, R. J. Sciotti, D. L. Hanna, M. D. Huband, L. M. Mullins, H. Cai, J. W. Gage, M. Lockard, M. R. Rauckhorst, R. M. Owen, M. S. Lall, M. Tomilo, H. Chen, S. P. McCurdy, M. R. Barbachyn, Bioorg. Med. Chem. Lett. 2009, 19, 5302.

[9] P. S. Charifson, A. L. Grillot, T. H. Grossman, J. D. Parsons, M. Badia, S. Bellon, D. D. Deininger, J. E. Drumm, C. H. Gross, A. LeTiran, Y. Liao, N. Mani, D. P. Nicolau, E. Perola, S. Ronkin, D. Shannon, L. L. Swenson, Q. Tang, P. R. Tessier, S. K. Tian, M. Trudeau, T. Wang, Y. Wei, H. Zhang, D. Stamos, J. Med. Chem. 2008, 51, 5243.

[10] G. S. Basarab, J. I. Manchester, S. Bist, P. A. Boriack-Sjodin, B. Dangel, R. Illingworth, B. A. Sherer, S. Sriram, M. Uria-Nickelsen, A. E. Eakin, J. Med. Chem. 2013, 56, 8712.

[11] S. P. East, C. B. White, O. Barker, S. Barker, J. Bennett, D. Brown, E. A. Boyd, C. Brennan, C. Chowdhury, I. Collins, E. Convers-Reignier, B. W. Dymock, R. Fletcher, D. J. Haydon, M. Gardiner, S. Hatcher, P. Ingram, P. Lancett, P. Mortenson, K. Papadopoulos, C. Smee, H. B. ThomaidesBrears, H. Tye, J. Workman, L. G. Czaplewski, Bioorg. Med. Chem. Lett. 2009, 19, 894.

[12] J. Zhang, Q. Y. Yang, J. B. Cross, J. A. C. Romero, K. M. Poutsiaka, F. Epie, D. Bevan, B. Wang, Y. Z. Zhang, A. Chavan, X. Zhang, T. Moy, A. Daniel, K. Nguyen, B. Chamberlain, N. Carter, J. Shotwell, J. Silverman, C. A. Metcalf, D. Ryan, B. Lippa, R. E. Dolle, J. Med. Chem. 2015, 58, 8503.

[13] L. C. Axford, P. K. Agarwal, K. H. Anderson, L. N. Andrau, J. Atherall, S. Barker, J. M. Bennett, M. Blair, I. Collins, L. G. Czaplewski, D. T. Davies, C. T. Gannon, D. Kumar, P. Lancett, A. Logan, C. J. Lunniss, D. R. Mitchell, D. A. Offermann, J. T. Palmer, N. Palmer, G. R. W. Pitt, S. Pommier, D. Price, B. N. Rao, R. Saxena, T. Shukla, A. K. Singh, M. Singh, A. Srivastava, C. Steele, N. R. Stokes, H. B. Thomaides-Brears, E. M. Tyndall, D. Watson, D. J. Haydon, Bioorg. Med. Chem. Lett. 2013, 23, 6598.

[14] J. T. Palmer, L. C. Axford, S. Barker, J. M. Bennett, M. Blair, I. Collins, D. T. Davies, L. Ford, C. T. Gannon, P. Lancett, A. Logan, C. J. Lunniss, C. J. Morton, D. A. Offermann, G. R. W. Pitt, B. N. Rao, A. K. Singh, T. Shukla, A. Srivastava, N. R. Stokes, H. B. Thomaides-Brears, A. Yadav, D. J. Haydon, Bioorg. Med. Chem. Lett. 2014, 24, 4215.

[15] J. B. Cross, J. Zhang, Q. Y. Yang, M. F. Mesleh, J. A. C. Romero, B. Wang, D. Bevan, K. M. Poutsiaka, F. Epie, T. Moy, A. Daniel, J. Shotwell, B. Chamberlain, N. Carter, O. Andersen, J. Barker, M. D. Ryan, C. A. Metcalf, J. Silverman, K. Nguyen, B. Lippa, R. E. Dolle, ACS Med. Chem. Lett. 2016, 7, 374.

[16] M. F. Mesleh, J. B. Cross, J. Zhang, J. Kahmann, O. A. Andersen, J. Barker, R. K. Cheng, B. Felicetti, M. Woodc, A. T. Hadfield, C. Scheich, T. I. Moya, Q. Y. Yang, J. Shotwell, K. Nguyen, B. Lippa, R. Dolle, M. D. Ryan, Bioorg. Med. Chem. Lett. 2016, 26, 1314. 
[17] A. E. Eakin, O. Green, N. Hales, G. K. Walkup, S. Bist, A. Singh, G. Mullen, J. Bryant, K. Embrey, N. Gao, A. Breeze, D. Timms, B. Andrews, M. Uria-Nickelsen, J. Demeritt, J. T. Loch, 3rd, K. Hull, A. Blodgett, R. N. Illingworth, B. Prince, P. A. Boriack-Sjodin, S. Hauck, L. J. MacPherson, H. Ni, B. Sherer, Antimicrob. Agents Chemother. 2012, 56, 1240.

[18] G. S. Basarab, P. J. Hill, C. E. Garner, K. Hull, O. Green, B. A. Sherer, P. B. Dangel, J. I. Manchester, S. Bist, S. Hauck, F. Zhou, M. UriaNickelsen, R. Illingworth, R. Alm, M. Rooney, A. E. Eakin, J. Med. Chem. 2014, 57, 6060.

[19] B. A. Sherer, K. Hull, O. Green, G. Basarab, S. Hauck, P. Hill, J. T. Loch, G. Mullen, S. Bist, J. Bryant, A. Boriack-Sjodin, J. Read, N. DeGrace, M. Uria-Nickelsen, R. N. Illingworth, A. E. Eakin, Bioorg. Med. Chem. Lett. 2011, 21, 7416.

[20] L. W. Tari, M. Trzoss, D. C. Bensen, X. Li, Z. Chen, T. Lam, J. Zhang, C. J. Creighton, M. L. Cunningham, B. Kwan, M. Stidham, K. J. Shaw, F. C. Lightstone, S. E. Wong, T. B. Nguyen, J. Nix, J. Finn, Bioorg. Med. Chem. Lett. 2013, 23, 1529.

[21] L. W. Tari, X. Li, M. Trzoss, D. C. Bensen, Z. Chen, T. Lam, J. Zhang, S. J. Lee, G. Hough, D. Phillipson, S. Akers-Rodriguez, M. L. Cunningham, B. P. Kwan, K. J. Nelson, A. Castellano, J. B. Locke, V. Brown-Driver, T. M. Murphy, V. S. Ong, C. M. Pillar, D. L. Shinabarger, J. Nix, F. C. Lightstone, S. E. Wong, T. B. Nguyen, K. J. Shaw, J. Finn, PLoS ONE 2013, 8, e84409.

[22] T. Tomašić, S. Katsamakas, Ž. Hodnik, J. llaš, M. Brvar, T. Solmajer, S. Montalvao, P. Tammela, M. Banjanac, G. Ergović, M. Anderluh, L. Peterlin Mašić, D. Kikelj, J. Med. Chem. 2015, 58, 5501.

[23] T. Tomašič, M. Mirt, M. Barančoková, J. Ilaš, N. Zidar, P. Tammela, D. Kikelj, Bioorg. Med. Chem. 2017, 25, 338.

[24] M. Gjorgjieva, T. Tomašić, M. Barančoková, S. Katsamakas, J. Ilaš, P. Tammela, L. Peterlin Mašič, D. Kikelj, J. Med. Chem. 2016, 59, 8941.

[25] M. Jukič, J. Ilaš, M. Brvar, D. Kikelj, J. Cesar, M. Anderluh, Eur. J. Med. Chem. 2017, 125, 500.

[26] N. Zidar, H. Macut, T. Tomašič, M. Brvar, S. Montalvao, P. Tammela, T. Solmajer, L. Peterlin Mašič, J. Ilaš, D. Kikelj, J. Med. Chem 2015, 58, 6179.

[27] N. Zidar, T. Tomašič, H. Macut, A. Sirc, M. Brvar, S. Montalvao, P. Tammela, J. Ilaš, D. Kikelj, Eur. J. Med. Chem. 2016, 117, 197.
[28] C. S. Schneider, J. Mierau, J. Med. Chem. 1987, 30, 494.

[29] M. Brvar, A. Perdih, M. Renko, G. Anderluh, D. Turk, T. Solmajer, J. Med. Chem. 2012, 55, 6413.

[30] GAMESS interface, ChemBio3D Ultra 13.0, ChemBioOffice Ultra 13.0, CambridgeSoft.

[31] T. A. Halgren, J. Comput. Chem. 1996, 17, 490.

[32] M. Rarey, B. Kramer, T. Lengauer, G. Klebe, J. Mol. Biol. 1996, 261, 470.

[33] M. Rarey, S. Wefing, T. Lengauer, J. Comput. Aided Mol. Des. 1996 $10,41$.

[34] BioSolve IT (GmbH), LeadIT version 2.1. 9.

[35] PyMOL, Delano Scientific LLC, San Francisco, CA, Available online at: http://pymol.sourceforge.net

[36] T. Baba, T. Ara, M. Hasegawa, Y. Takai, Y. Okumura, M. Baba, K. A. Datsenko, M. Tomita, B. L. Wanner, H. Mori, Mol. Syst. Biol. 2006, $2,1$.

[37] CLSI. Methods for Dilution Antimicrobial Susceptibility Tests for Bacteria That Grow Aerobically; Approved Standard-Ninth Edition. CLSI document M07-A9. Clinical and Laboratory Standards Institute, Wayne, PA 2012.

\section{SUPPORTING INFORMATION}

Additional Supporting Information may be found online in the supporting information tab for this article.

How to cite this article: Tomašič T, Barančoková M, Zidar N, Ilaš J, Tammela P, Kikelj D. Design, synthesis, and biological evaluation of 1-ethyl-3-(thiazol-2-yl)urea derivatives as Escherichia coli DNA gyrase inhibitors. Arch Pharm Chem Life Sci. 2018;351:e1700333. https://doi.org/10.1002/ardp.201700333 